\title{
The Access Model for Music and the Effect of Modification, Trial, and Sharing Usage Rights on Streaming Adoption and Piracy
}

\section{William Hampton-Sosa}

City University of New York, Brooklyn College, New York City, United States, whamptonsosa@brooklyn.cuny.edu

Received 12 July 2018; received in revised form 21 September 2018; accepted 12 November 2018

\section{Abstract}

The access economy business model has been applied to a wide range of digital goods and services such as software, movies, music, and books. The digital platforms that manage transactions between buyers and sellers enable product rights owners to define product usage rights with a great deal of precision. In this paper music product usage rights for digital consumption and platform attributes of music streaming systems are discussed and a model for digital music streaming system adoption and digital piracy is presented. The results of a quasi-experiment suggest that the perceived freedom to tryout, modify, and share digital music products contribute to both perceived usefulness and perceived enjoyment of a product format and the music streaming system. In turn, perceived usefulness and perceived enjoyment lead to the intention to adopt a music streaming system. The perceived usefulness of a music streaming system is associated with a reduction of pirating intention.

Keywords: Music streaming, Digital piracy, Access economy, Usability, Enjoyment, File sharing, Usage rights, Quantitative 


\section{Introduction}

The access economy business model emphasizes user access to products and services in lieu of ownership. The model has disrupted many industries including transportation, real estate, software, finance, and media [34], [115], [138]. With respect to the music and film industry, ownership of physical media continues to decline while access to streaming content continues to become more widely adopted [31], [48], [52], [113], [128]. In this industry, the access economy business model is exemplified by content streaming services such as Netflix and Spotify, both of which have become very popular and successful. As of April 2018, Netflix claimed 117 million members, a growing subscriber base, and operated in 190 countries [86]. Its net income for 2017 was $\$ 560$ million on revenues of approximately $\$ 11.7$ billion [86]. Spotify has yet to make a profit, but the company's subscriber base continues to grow [110], [112] and it is among the most popular sources for streaming content [28], [30]. Spotify successfully launched an initial public offering on April 3, 2018 that valued the company at approximately $\$ 25$ billion [112].

With respect to music consumption specifically, increasing numbers of consumers have embraced music streaming systems (MSSs). These and other similar services emphasize easy access to content without the user having to assume ownership along with all of the associated content management responsibilities. But it is a very crowded and competitive marketplace [88], with relatively low entry barriers [37], that already has had many winners and losers [74]. Even the larger firms in terms of subscriber base such as Spotify and Apple Music can only claim a relatively small percentage of the population of potential users many of whom have yet to adopt any MSS at all [30], [50]. As a result, there is a pressing need to better understand the MSS features that appeal most to users and that can continue to drive adoption. Until now there has been very little research in this area.

Another issue addressed by this research concerns digital piracy, which remains a persistent challenge for product rights owners (PROs) [81], [82], [83]. In fact, while some forms of digital piracy such as peer-to-peer (P2P) file sharing may have declined, other forms such as stream ripping have become much more widespread [81], [82], [83]. The loss in revenue and profit remains significant and results in substantial harm to PROs and artists [80].

Digital piracy has been addressed in numerous ways over the years with varying degrees of success. No single approach has proved to be the proverbial silver bullet and all indications are that an effective strategy must be multifaceted. The access economy business model is an additional approach with significant potential and some have suggested that it could already be having an effect toward reducing digital piracy [131]. This research examines the premise that if the access economy business model in the form of MSSs is properly applied to the music industry in ways that are appealing to users it could reduce digital piracy and mitigate its negative effects.

\subsection{The Access Economy Business Model}

In many respects, the access economy business model concept is not really novel. Leasing as an alternative to ownership has long been commonplace for many types of products such as tools and equipment, vehicles, and real estate. What continues to evolve is the expanding variety of products and services offered by an increasing number of firms using the model [34].

The access economy business model is sometimes conflated with the sharing, peer-to-peer, on-demand, collaboration, gig, platform, or mesh economy business models. These terms are not really interchangeable and there have been efforts to distinguish, define, and clarify the different business models [11], [33], [55], [114]. Perhaps it should not come as a surprise that consumers seem confused [111]. How these models differ has to do in large part with differences in the exchange relationships and the context in which transactions take place.

For example, the peer-to-peer economy business model may be appropriate for describing the types of exchanges facilitated by firms such as Craigslist and eBay. In this case, transactions are decentralized and users get what they need directly from each other through the buying and selling of goods and services. An intermediary facilitates transactions but generally does not own the assets or means of production and the emphasis is on user ownership and private consumption.

In contrast, the sharing economy business model tends to characterize exchanges facilitated by firms such as Airbnb, Uber, and ZipCar. In this business model, firms may or may not own the assets and means of production. The emphasis is on providing shared access to a product or service instead of facilitating private ownership and exclusive consumption by the user. However, sharing implies a sense of community and reciprocity and these are often not factors in many transactions. In many cases, the sharing economy business model is better described as the access economy business model, which is a broader and more generalized way to describe the consumption of goods and services that does not entail ownership nor requires a sense of community as a necessary feature. 
The access economy business model is appealing to users for manifold reasons. It offers a way to avoid many of the issues and inconveniences associated with ownership such as the need to organize product collections, allocate storage, provide maintenance, purchase insurance, and maintain security. For example, the ownership of digital products such as computer software often requires that users install and configure software, manage memory allocations, create back up copies, plan for possible system failures, manage system upgrades, and install up to date security software. With respect to music and film, the access economy business model realized by MSSs obviates the need to purchase DVDs, CDs, or downloadable file objects that would then need to be stored, organized, and maintained. Instead, content can be streamed over the Internet to personal computers, laptops, tablets, mobile devices, or home entertainment systems. Consumption can take place on demand in real time or scheduled for later enjoyment.

The access economy business model can also be very cost effective. Passenger vehicles are relatively expensive to acquire and maintain for the average consumer and they generally sit idle the vast majority of the time. Car sharing services give consumers easy and affordable access to vehicles on demand and without the hassle and expense of ownership. Similarly, with respect to music, a large physical music collection is expensive to acquire and even the most devoted music fans only listen to their favorite artists a relatively small percentage of the time. MSSs greatly reduce the costs of acquiring music collections and they afford users access to huge libraries of content for a relatively small monthly subscription fee. In addition, MSSs offer other benefits such as ease of discovery and the ability to try out new music before making a purchasing commitment.

Many businesses find the access economy business model appealing because it facilitates matching supply with demand even in cases where markets are small, highly fragmented, and dynamic. Digital technologies allow firms to develop the platforms that create markets, facilitate transactions, and handle trust management. Importantly, digital technologies and modern transaction platforms can ease compliance with a wide range of nuanced usage rights and restrictions and this gives firms greater latitude to design value propositions with greater specificity and less transaction friction.

\subsection{Access Economy Business Model in the Music Industry}

The rising popularity of the access economy business model in the music business has been dramatic with the development and evolution of MSSs. In March of 2016, the Recording Industry Association of America reported that MSSs generated $\$ 3.9$ billion in sales in the United States and this represented $51 \%$ of all revenues, while at the same time sales of CDs continued to decline [101]. This was a major milestone for the industry. Other forms of media such as movies on DVDs have also declined while content streaming on services such as Hulu, Netflix, and Amazon have risen [29].

Some of the most popular MSSs disrupting the music industry include Apple Music, Amazon Prime, Amazon Music Unlimited, Napster, Spotify, and Tidal, but they represent only a small fraction of the estimated 450 MSSs that are currently available or in development [88]. Many other MSSs such as Last.fm, Rdio, Guvera, and Milk Music have already come and gone [74]. The impact of MSSs has been felt across the music industry and affects not only the consumers of music, but also the creators of content. Artists now have better distribution options and can reach niche audiences more easily. Users can enjoy access to larger libraries of music and better options for search and discovery.

There are several factors driving the development of so many MSSs. They can positively impact overall music sales [2], [64], [133] and may displace some music piracy [131]. MSSs can drive other types of revenue sources such as live concerts [85]. Some music labels are experimenting with the concept of establishing niche streaming services in order to better promote their own artists, gain greater control over their investments, and claim a greater share of revenues [118]. Independent music labels are creating their own streaming services in order to give artists a better deal than they could otherwise achieve by working with some of the larger and more popular MSSs [118]. Some PROs are simply responding to changing consumer preferences for music consumption that are made possible by technological advancements such as improved and deeper penetration of wireless broadband communications.

Currently, a small number of MSSs dominate, but it is clear that the market is very dynamic. The rise and fall of many early pioneers suggests that the current dominant group of successful MSSs is likely to be fleeting and therefore any status quo is temporary and cannot be taken for granted by PROs, users, and investors. There is a need to better understand the drivers of MSS appeal in order to satisfy shifting user needs and expectations. Developing a competitive advantage through innovation and differentiation is important and remains a major challenge.

\subsection{Adoption of Music Streaming Systems}

Our understanding of what drives MSS adoption is limited, but we do have some initial findings. Factors that drive MSS adoption include the importance of community and creativity facilitation [40] and system and information quality [39]. When users pay subscription fees or consume advertising in exchange for access to large libraries of music, perceived ownership is often less defined, transient, and ambiguous. Nevertheless, perceived ownership is important to users and it is positively linked to MSS adoption [108]. Perceived music ownership is often influenced by a desire 
to achieve identity, sense of place, and control, which can then lead to loyalty, empowerment, and social rewards [108]. This research addresses another set of factors that drive MSS adoption.

MSSs vary a great deal in terms of system processes, system requirements, product formats, product features, technology integration, mobility, and interface design. The nature of digital platforms, digital content, and the various protocols that enable streaming allows PROs the ability to define a broad and highly differentiated set of music product usage rights (MPURs) and platform attributes. These factors can influence the appeal of a MSS. Platform attributes and MPURs can be determined by the rules defined and managed by the platform and the encoding, i.e., format of the music product. MPURs can be defined by user agreements and enforced through legal measures. They can also result from deliberate software and hardware design intention or as an unintended byproduct of that design. By defining and controlling the set of MPURs, PROs can create a differentiated user experience that can be similar to traditional ownership, enhanced, or highly circumscribed. MPURs can also affect the perceived usefulness and enjoyment of a MSS.

With respect to MPURs, PROs can among other things determine if users can share a file, with whom they may share it, and for how long. PROs can determine whether users may download and consume a music file object when not online. The streaming object may be encoded to better handle low bandwidth conditions. A PRO may offer downloadable formats that could be repurposed for projects such as presentations and video productions. Design considerations regarding specific MPURs and their influence on the perceived usefulness and perceived enjoyment of a particular MSS and its adoption has not received much research attention.

The supposition that MPURs influence usefulness and enjoyment of MSSs and ultimately system adoption is suggested by the theory of technology acceptance. The theory provides a basis for exploring how specific MPURs determine usefulness and enjoyment. Table 1 presents a summary of several common MPURs and suggested definitions. The definitions are based on notions of fair use, copyright law, traditions, and norms regarding the consumption of music. This research focuses on three specific product features that relate to modification, trial (i.e., examination), and sharing.

Table 1: Digital music product usage right definitions

\begin{tabular}{|c|c|}
\hline Usage Right & Definition \\
\hline Privacy & $\begin{array}{l}\text { The right to privacy is the freedom to keep personal identity, profile information, } \\
\text { preferences, relationships, and consumption behavior shielded from outside scrutiny. It } \\
\text { is the freedom from intrusion and monitoring. }\end{array}$ \\
\hline Confidentiality & $\begin{array}{l}\text { The right to confidentiality is the freedom to keep personal identity, profile information, } \\
\text { preferences, relationships, and consumption behaviour secret among authorized } \\
\text { parties. The right to confidentiality implies that an individual is entitled to control how } \\
\text { personal information is handled, whether it can be shared, and whether certain } \\
\text { decisions can be made based on that information. }\end{array}$ \\
\hline Anonymity & $\begin{array}{l}\text { The right to anonymity is the freedom to keep one's personal identity secret and } \\
\text { separate from profile information, preferences, relationships, and consumption } \\
\text { behavior. }\end{array}$ \\
\hline $\begin{array}{l}\text { Continuing } \\
\text { access }\end{array}$ & $\begin{array}{l}\text { The right to continuing access means that a product does not permanently expire, } \\
\text { deteriorate, or become inoperable before the end of its normal life. }\end{array}$ \\
\hline Backup & $\begin{array}{l}\text { The right to back up content for personal use is the freedom to make at least one copy } \\
\text { of a product on an appropriate medium that could replace the original item. }\end{array}$ \\
\hline Examination & $\begin{array}{l}\text { The right to examination is the freedom to adequately inspect, test, and assess the } \\
\text { suitability of a product before making a final purchasing decision. }\end{array}$ \\
\hline Sampling & $\begin{array}{l}\text { The right to sampling is the freedom to select and consume a portion, subunit, or } \\
\text { subsection of a product. }\end{array}$ \\
\hline Time shifting & The right to time shifting is the freedom to consume a product at any time. \\
\hline Space shifting & $\begin{array}{l}\text { The right to space shifting is the freedom to consume a product at any preferred } \\
\text { location. }\end{array}$ \\
\hline Platform shifting & $\begin{array}{l}\text { The right to platform shifting is the freedom to select the software and hardware } \\
\text { combination to enable consumption. }\end{array}$ \\
\hline
\end{tabular}




\begin{tabular}{|l|l|}
\hline \multicolumn{2}{|l|}{ Table 1: continuation } \\
\hline Sharing & $\begin{array}{l}\text { The right to sharing is the freedom to permit others to experience a product. Sharing } \\
\text { parameters are numerous and can defined by the number of times a product can be } \\
\text { shared, the number of people with whom a product can be shared, the period of time } \\
\text { during which a product can be shared, the number of simultaneous users that can be } \\
\text { allowed to experience a product, and the relationship to the user. Parameters can also } \\
\text { include the range of features that can be shared. }\end{array}$ \\
\hline Modification & $\begin{array}{l}\text { The right to modification is the freedom to make changes to a product, which can range } \\
\text { from simple edits to extensive transformations. }\end{array}$ \\
\hline Transcoding & The right to transcode is the freedom to change the file format. \\
\hline Metadata & $\begin{array}{l}\text { The right to add metadata is the freedom to add information in the form of tags, } \\
\text { descriptions, comments, or ratings. }\end{array}$ \\
\hline $\begin{array}{l}\text { Reverse } \\
\text { engineering }\end{array}$ & $\begin{array}{l}\text { The right to reverse engineer a product is the freedom to explore its coding, design, and } \\
\text { composition. }\end{array}$ \\
\hline $\begin{array}{l}\text { Advertising-free } \\
\text { consumption }\end{array}$ & $\begin{array}{l}\text { The right to advertising-free consumption is the freedom to consume a product without } \\
\text { having to also consume marketing messages. }\end{array}$ \\
\hline Fair use & $\begin{array}{l}\text { The right to fair use refers to a legal principle regarding the use of works that are } \\
\text { protected by copyright and includes software, movies, music, books, and images. The } \\
\text { purpose of the legal principle is to facilitate the freedom of expression by permitting } \\
\text { criticism, parody, commentary, reporting, education, and scholarship. }\end{array}$ \\
\hline
\end{tabular}

\subsection{Music Streaming Systems and Digital Piracy}

A second issue addressed by this research concerns how MPURs can influence digital piracy. Notwithstanding the rise in sales for most types of music and film on streaming services, many PROs assert with some justification that overall they have lost revenue as a result of digital piracy. Quantifying the specific impact of digital piracy is challenging, but one study found that a one percent increase in the music piracy rate resulted in a 0.6 percent decrease in music sales [7]. In addition, a one percent increase in the Internet penetration rate resulted in more than a one percent decrease in music sales [7].

Some caution that the decline in music sales in the 2000s may not be related to digital piracy, but rather to the onetime shift from analog content to digital CDs, which became the popular format in the 1990s [89]. This shift led to a big increase in music sales. The subsequent drop off in music sales therefore may have been due in part to a saturation of the market for CDs.

The impact of digital piracy can also be disproportionate. Movies that are widely released tend to suffer from digital piracy; however, smaller releases may actually benefit because of the promotional effects that piracy can provide [93]. This dynamic has been observed for music as well [95]. The promotional effects of piracy have also been noted in markets that are underdeveloped and in which access is therefore limited [76]. It is also possible that a certain level of music piracy can drive sales in other revenue-generating areas providing a net benefit to PROs [78].

Notwithstanding some of the benefits of piracy, some facts are clear. In the regions that make up the majority of Internet users and bandwidth consumed, which includes North America, Europe, and the Asia-Pacific regions, the amount of bandwidth used for copyright infringement between 2010 and 2012 increased by $159.3 \%$ and represented $23.8 \%$ of total bandwidth consumption [87]. The number of Internet users explicitly seeking pirated content during 2013 rose by $9.9 \%$ and represented a quarter of the total Internet population [87]. The number of page views recorded on websites that focused on digital piracy increased nearly 10\% between November 2011 and January 2013 [87]. Since then indications are that things have not gotten much better if at all.

- $\quad$ In 2017, there were 27.9 billion visits to media piracy sites in the U.S. alone [83].

- In 2016, there were 179.55 billion visits to media piracy sites worldwide and included those that offered unauthorized streaming, public torrents, web downloads, stream rippers, and private torrents [83].

- In 2017 , more than $25 \%$ of all consumers, ages $15-45$, indicated that they had used unauthorized file sharing services to stream or download music [5]. 
While digital piracy seems to have moderated in some markets, especially with respect to peer-to-peer file sharing, McKenzie [75] cautions that many sophisticated users have switched to unmonitored methods to avoid detection or make use of relatively accessible geo-blocking software that can effectively hide P2P file-sharing activity. In addition, the fastest growing form of digital piracy now entails stream ripping, which is facilitated by widely available and easy to use software tools [52]. Users are also increasingly consuming content at illegal streaming sites, which in 2016 was the preferred method of delivery for pirated media worldwide [83]

The factors that drive digital piracy, the conditions that facilitate it, and the manner in which it can be addressed are complex. The criminology perspective suggests that deterrence [79], [102], [105], [134], [141], neutralization [49], self-control [43], [46], [71], and social learning [77], [137] influence digital piracy. Observing and interacting for long periods of time with peers who pirate content [71], [105], having an innate lack of self-control [27], [44], [45], [71], prior downloading experience [45], [117], and rationalizing the behavior through the denial of harm and other negative consequences [49] also influence digital pirating behavior. There are several risks associated with digital piracy [84], but if the benefits outweigh the risks, some may choose to engage in digital piracy [10], [16], [105], [141]. This is consistent with studies that highlight economic considerations. If the benefits outweigh the financial costs users may choose to acquire content illegally [10], [19], [63], [68], [124].

Some view digital piracy as a moral or ethical issue [139] that can be influenced by moral recognition, judgment, intensity, magnitude of the consequences [14], [23], [59], [62], [70], [119] and religiosity [13]. It can also be a function of proximity to those who are harmed by digital piracy [16]. However, some do not recognize a moral imperative because attributions of harm to artists or record labels does not resonate [66]. Indeed, not only do a substantial number of users not view digital piracy as harmful [25] a surprising number are unable to recognize it when they see it [80].

Several studies have addressed digital piracy using social cognitive theory [53], [63]. Others have relied on the theory of reasoned action and planned behavior and show that attitudes, perceived behavioral control, and social norms provide a basis to explore a wide range of specific motivating factors that relate to digital piracy [4], [9], [17], [18], [62], [67], [79], [121]. For example, research has demonstrated that attitudes toward digital piracy can be influenced by Machiavellianism [4], [119], antipathy toward the music industry [62], [135], high costs and low benefits [67], self-efficacy [9], anticipated guilt [126], and idolatry [125]. National culture can also be a factor [56], [120], [136].

Lowry et al. provide a recent meta analysis and found that four sets of factors maximize the prediction of digital piracy and includes outcome expectancies, social learning, self-efficacy and self regulation, and moral disengagement [69]. But digital piracy can also be influenced by technology considerations such as the quality of infrastructure and access to computers. For example, greater bandwidth availability tends to facilitate and encourage unauthorized downloading [8]. Being knowledgeable about computers is positively linked to digital piracy [73]. Given the many factors that influence digital piracy several strategies to address the issue are possible; however, selecting the right approach can be challenging because not all digital pirates are motivated in the same way. There are different psychographic profiles and digital pirates may respond differently to specific anti-piracy strategies [25].

Some have suggested that Internet service providers should work together with content providers to combat piracy, and this often does happen; however, under certain market conditions, the incentives to collaborate are sometimes insufficient [25]. Ultimately, the prevalence of digital piracy may simply reflect a market failure in that PROs are not offering consumers what they want and who are then motivated to seek alternatives [35]. With this in mind, this research explores the idea that if MSSs are properly designed in specific ways that are appealing to users system adoption may follow [39], [40]. An appealing MSS may also dissuade users from engaging in digital piracy. The premise is that design features should focus on MPURS that influence the usefulness and enjoyment of a MSS. A framework for exploring this approach is the expanded technology acceptance model (TAM) [20]. There are numerous MPURS that may motivate the purchasing and downloading of content. To date little research in this area has been done.

To summarize, it is clear that digital piracy remains a challenge. Furthermore, the trends are clear regarding the increasing adoption of MSSs. What are not clear are how specific MPURs and platform attributes drive MSS preference and influences digital piracy. Using a quasi-experimental approach and a survey of user responses, this research attempts to provide empirical support for the following assertions.

1 A MSS can be viewed as an information system and its adoption can be explained using an expanded TAM

2 The TAM can also be used to explain some of the factors that influence user willingness to engage in digital piracy.

3 Perceived MSS usefulness and perceived MSS enjoyment are platform attributes that positively influence MSS adoption and negatively influence unauthorized downloading intention.

4 Perceived product format usefulness and perceived product format enjoyment are product attributes that influence perceived MSS usefulness and perceived MSS enjoyment, respectively. 
5 Perceived ease of product modification, the perceived ease of product trial (i.e., product examination), and the perceived ease of product sharing are specific MPURs that influence perceived product format usefulness and perceived product format enjoyment.

The rest of this paper is organized as follows. The next section is the theoretical development of the research model, which is summarized in Figure 1. This is followed by a discussion of the research methodology and a presentation of the research results and analysis. The paper concludes with a discussion of the findings, research limitations, and possible future research directions.

\section{Theoretical Development and Research Model}

There are several technology acceptance models described in the literature. One of the earliest is the theory of diffusion of innovations in which Rogers proposed that the adoption of an innovation occurred in stages and included understanding, persuasion, decision, implementation, and confirmation [103]. He also posited that a chasm between early adopters and early majority must be crossed before widespread acceptance occurs [103]. Informed by the theory of reasoned action and the theory of planned behavior Davis et al. proposed an alternative, the TAM [24]. According to the TAM, technology acceptance is a function of perceived usefulness and perceived ease of use [24]. The model has been further developed, refined, and modified over time [65], [72], [122]. The TAM has been applied to wide range of information technologies to explain their acceptance. It has been widely used in digital piracy research as well [4], [9], [18], [39], [40], [62], [67], [79], [121] and provides a basis for exploring a wide range of factors that affect attitudes toward digital piracy.

\subsection{Perceived Ease of Use, Perceived Usefulness, and Perceived Enjoyment}

The TAM was originally applied to business productivity tools used in offices; however, technologies differ and can be categorized as either utilitarian or hedonic in nature [42]. Utilitarian technologies "provide instrumental value to the user" [42]. Their use is motivated by factors external to the interaction between the user and the system itself and, as a result, design considerations are focused on achieving efficiency and effectiveness. In contrast, the use of hedonic technologies is motivated by the interaction with the technology itself. "Hedonic systems provide self-fulfilling value to the user" [42]. Users interact with hedonic technologies such as video games in large part because they are fun and exciting. When Heijden's version of the extended TAM is applied to hedonic technologies, the construct of perceived enjoyment usually emerges as a strong predictor of technology acceptance [42].

A MSS is an information system that has both hedonic and utilitarian qualities. Utilitarian qualities are reflected in the design of the exchange interface, process and system features, and product formats. MSSs can support many phases of the user buying lifecycle including awareness, interest, consideration, purchase, support, repeat purchases, and referral. MSSs feature tools to find music, organize titles, sort through rankings and commentary, access product information, and facilitate music sharing. MSSs vary in terms of portability and platform independence. PROs can offer downloadable or streaming files unencumbered with digital rights management (DRM) software or instead attach specific usage rights that circumscribe music product use. PROs can offer file formats with a high degree of fidelity, but the tradeoff may be slower transmission rates. MSSs can be designed in ways that enhances utility by enabling product modification or repurposing.

The hedonic qualities of a MSS contribute to its enjoyment. For example, the consumption of music allows the individual "to regulate arousal and mood, to achieve self-awareness, and as an expression of social relatedness" [104]. Users can experience pleasure by using the many features typically incorporated into MSSs. Recommendation algorithms and search tools allow users to enjoy the discovery of new music. It can be entertaining to read artists' bios, news, and commentaries from fans and professional critics. Learning about the influences that shaped artists and their subsequent impact on others can be fun for fans. There is often enjoyment in creating and sharing playlists. It can be fun to take your music with you anywhere you go by accessing music libraries in the cloud. MSS libraries differ in terms of the number of titles available at any given time. MSSs differ in terms of the number of permissible playback devices. MSSs may require a relatively steady broadband connection for uninterrupted playback that may not always be available. All of these factors impact the ability to enjoy a MSS and its utility as well.

There are many reasons that a user may choose a particular music consumption platform, legal or otherwise. One that is useful, easy to use, and enjoyable is more likely to be preferred by a user and it may not matter whether it is a legal MSS or an unauthorized downloading platform. A MSS may be promoted by highlighting its superiority over traditional radio because they facilitate personalization, music discovery, music for any occasion, easy sharing, ease of personal expression, and mobility [36]. Others have highlighted the practical advantages of music streaming such as less clutter, greater choice, easier access, and greater mobility [108]. In order to appeal to a wide range of users with respect to usefulness, ease of use, and enjoyment, a MSS should incorporate a wide range of features. 
For example, there are several music discovery tools including radio recommendation, regional charts, offering categories of music based on genres and moods, and by following friends on social media. However, the preference for these different features tends to vary depending upon individual preference characteristics related to insight, diversity, and openness [116].

MSSs that are perceived as useful, enjoyable, and easy to use attract users [20], [106], [127] This study posits that it could also dissuade users from adopting unauthorized alternatives. This notion is supported by evidence that suggests users may be turned off by MSS products that are cumbersome to use or that come with too many restrictions [109]. For the purposes of this research the following three factors are adapted from Heijden's research [41], [42]. Perceived MSS usefulness is defined as the degree to which a person believes that a MSS would enhance his or her ability to consume music. Perceived ease of use is defined as the degree to which a person believes that using a MSS would be free from effort. Perceived MSS enjoyment is defined as the extent to which the act of using a MSS is perceived to be enjoyable in its own right separate from any performance considerations. Thus we have the following hypotheses.

\section{H1: Perceived MSS usefulness is negatively related to unauthorized downloading intention.}

H2: Perceived MSS usefulness is positively related to MSS purchasing intention.

H3: Perceived MSS enjoyment is negatively related to unauthorized downloading intention.

H4: Perceived MSS enjoyment is positively related to perceived MSS purchasing intention.

H5: Perceived MSS ease of use is positively related to perceived MSS usefulness.

H6: Perceived MSS ease of use is positively related to perceived MSS enjoyment.

\subsection{Perceived Product Format Usefulness and Perceived Product Format Enjoyment}

Digital products, through the design of software and hardware, can be imbued with a wide range of specific, but malleable usage rights. This is the case when content is shared using DRM tools. Even when the core content offering remains unchanged from one PRO to the next, a product can still be highly differentiated. This affords the PRO the ability to offer any of a number of value propositions in terms of price, quality, and usage rights. For example, with respect to sharing rights, a PRO can determine whether or not a product can be shared in the first place, with whom, the length of time, and whether a product can be shared with a full range of usage rights or only a subset. A PRO can also determine to what extent a product can be modified or repurposed. For example, PROs can choose to offer music content as a stream or as an MP3 download. The latter is much easier to incorporate into creative projects such as slideshows and home movies. Downloadable file formats in general often allow for a greater range of uses such as offline consumption. A user can often experience greater mobility with a downloadable file object because there is no dependence on a steady Internet connection. In general, differences in usage rights, by intentional design or as a byproduct of that design, influence the usefulness and amount of enjoyment that a user can experience with a product.

Product formats that restrict usage rights reduce economic, social, and economic utility and this could motivate users to seek alternatives that include engaging in digital piracy [107]. This was demonstrated in a study in which certain types of usage restrictions were linked to an increased preference for pirated content [1]. This is consistent with another study that showed that individuals do prefer legal music, but the appeal is influenced by various considerations such as the quality of the audio, whether or not the content was free of advertising, latency issues, and whether the supported formats allowed users to both stream and download content [22], [129], [130]. Given the different file formats that are available and how this can influence usefulness and enjoyment, the following two hypotheses are put forth.

\section{H7: Perceived product format usefulness is positively related to perceived MSS usefulness.}

H8: Perceived product format enjoyment is positively related to perceived MSS enjoyment.

\subsection{Perceived Ease of Product Modification}

There are several factors that seem to contribute toward the perceived usefulness and perceived enjoyment of a digital music product. This study focuses on three specific factors - perceived ease of modification, perceived ease of product sharing, and the perceived ease of product trial. The ability to modify a product would be important to those involved in creative activities such as developing videos. Before the widespread availability of inexpensive digital editing tools such as Apple Garageband, the modification of analog products such as music and film could be difficult, expensive, and time-consuming. It often required a great deal of knowledge and expertise that could generally only be acquired through extensive training and experience. It required access to expensive equipment and skilled staff that were usually beyond the reach of the average user. Today, this is no longer the case. 
The quality and ease of using editing software and the availability of inexpensive hardware allows users to more easily experiment and express themselves creatively. It has become easier to modify digital content in order to facilitate specific consumption needs. As a result, users are increasingly becoming less passive [47], [54], [97], [98], [99]. Web technologies are now sufficiently mature and provide the average user with means to creatively modify and integrate static and dynamic content from numerous sources, such as Instagram, YouTube, and Google into multimedia projects and applications.

The user modification of digital content can vary substantially. Some modifications are relatively simple and straightforward. In transcoding and resampling, digital bits may be altered, but changes may not be noticeable to the end user. For example, a user may convert files on a standard CD to an mp3 format to permit playback on mp3 devices or to simply reduce file size. Some types of modification do not alter the core content but rather the metadata. An example of this is tagging by members of a social network in order to better identify and categorize content. It is possible for users to create annotations in digital products by attaching or embedding text, audio, and video. Google enables users to create customized maps. Other types of modifications, such as remixes and mashups, can alter the digital file to create something derivative or highly original works of art.

PROs can impede a user's ability to modify a product in several ways. One way is by providing streaming content exclusively instead of downloadable file objects that could be imported directly into an editing program. A PRO could also offer products protected by some form of DRM technology, restrict the consumption of products to within closed proprietary environments exclusively, or employ strategies of deterrence to discourage unauthorized modifications.

The easier it is to modify a product to satisfy utilitarian needs the more useful the product to the user. In addition, the ability to easily modify a product means that a user could tailor it in ways that could add to its enjoyment. For the purposes of this research, perceived ease of modification is adapted from the TAM and is defined as the degree to which the content or purpose of a particular product can be customized, personalized, or adapted free of effort [90].

\section{H9: Perceived ease of product modification is positively related to perceived product format usefulness.}

H10: Perceived ease of product modification is positively related to perceived product format enjoyment.

\subsection{Perceived Ease of Product Sharing}

The ease of sharing refers to the freedom to share a product with others. For the user, the importance of sharing is partially driven by an individual's need for belonging and a sense of community. This is especially the case for digital culture products such as music. Sharing digital culture products is a way in which individuals express ideas, emotions, and identity, and in the process, establish relational ties. Digital products such as music can also be viewed as a resource and making them available to others is a way to signal trust, goodwill, and generosity. Sharing encourages reciprocity, can strengthen bonds between exchange partners, and can lead to the formation of social capital. Reciprocity as a driver in peer-to-peer (P2P) file exchanges has been empirically supported [32].

Sharing can also be something that is just fun to do. It helps users discover new products and ideas and other likeminded individuals with similar interests. Sharing could also be motivated by utilitarian considerations. A user may decide to share a product in the anticipation of some tangible benefit in return. Users are sometimes reminded by file-sharing software or by members of a file-sharing community to provide resources. By contributing bandwidth and files to file-sharing networks, users help to reduce congestion, facilitate search, and improve the overall experience for everyone on the network [21].

A product such as digital music can be shared in various ways. It can be played publically at a dance hall or at a private party. Users can exchange digital files or links to streaming content. Digital files can be shared privately through e-mail and virtual private networks or by posting to publicly accessible websites such as YouTube, Instagram, DropBox, or MediaFire. A user can download and exchange disk copies of a file. When sharing a product, a user can often choose to transfer a product with a full or circumscribed set of usage rights.

As with modification rights, depending on the characteristics of the digital product and the parameters of the exchange process, the ability to share a product can be greatly facilitated or restricted by the PRO. The PRO can choose to program rights and restrictions into the digital object itself or the consumption platform. The PRO may allow the product to be shared broadly or restrict sharing by limiting the number of potential recipients or the length of time allowed for sharing.

For the purposes of this research, the original TAM construct is adapted. Perceived ease of product sharing is defined as the degree to which the user of a particular product can allow others to consume, use, experience, or enjoy the product, free of effort [90]. Perceived ease of product sharing should contribute to both the overall usefulness and enjoyment of a digital culture product. 
H11: Perceived ease of product sharing is positively related to perceived product format usefulness.

H12: Perceived ease of product sharing is positively related to perceived product format enjoyment.

\subsection{Perceived Ease of Product Trial}

The perceived ease of product trial refers to the ease in which a user can experience and assess a product through sampling, testing, or some other form of exploration. The importance of this variable has been suggested by research related to diffusion theory and product adoption [103]. Before users commit to the purchase of a product they usually need to assess whether the product can satisfy their specific functional, quality, or enjoyment needs and preferences. The ability to easily consider a product can help users save money and reduce the risk of buyer's remorse. In addition, product trials can be a source of enjoyment for the user. The process of discovering and checking out digital music can be entertainment in and of itself since it involves gathering information and knowledge, fine-tuning a collection and possibly discovering new artistic insights.

The PRO can make it easy to assess digital music in a variety of ways. They can offer users low-resolution streams or truncated versions of downloadable file objects. A PRO can offer a file object or link with an expiration date. A PRO can offer unlimited access to an entire library of content or to only a circumscribed number of music tracks. A PRO can assist the user with recommendations based on past purchasing behavior or by comparison to other users with similar buying patterns.

For the purposes of this study, the perceived ease of product trial is adapted from the TAM and defined as the extent to which a product can be assessed, free of effort, before making a commitment to acquire the product [90]. A product that is easy to consider, try out, and experiment with can lead to user enjoyment. A product that is easy to consider for a variety of purposes is useful to the user. The perceived ease of product trial contributes to its overall usefulness and enjoyment.

\section{H13: Perceived ease of product trial is positively related to perceived product format usefulness.}

H14: Perceived ease of product trial is positively related to perceived product format enjoyment.

\subsection{General Attitude Toward Unauthorized Downloading}

Users develop a general attitude toward digital piracy over time. They develop habits and become accustomed to certain behaviors, especially if they experience mostly benefits and few negative consequences. Habits with respect to digital piracy may reflect an environment in which digital pirating activities are common and socially accepted. Under such circumstances, individuals can become acclimated to piracy and may continue developing their abilities for acquiring digital content through piracy. Pirating habits and experience with positive outcomes tend to foster positive attitudes toward digital piracy and several studies show that to be the case [3], [84], [94], [140].

To be clear, the construct examined in this model is not the subject's attitude toward unauthorized downloading that is formed during the limited encounter with the MSS over a short duration, as was the case in this study. This construct is usually part of the TAM and is an immediate precursor to the intention to engage in a particular behavior and has been validated in numerous studies. In order to simplify the model, this construct was not included. Instead, the model examines an individual's general attitude toward digital piracy and its influence on behavioral intention. General attitude toward unauthorized downloading is established over time and it is expected that this variable will have a substantial influence on downloading intention.

H15: General attitude toward unauthorized downloading is positively related to downloading intention.

\subsection{Perceived Cost of the Product}

Many studies indicate that perceived cost is a major factor that positively influences digital piracy [8], [56], [106]. Indeed, in a 2015 survey, 66\% of those using illegal file sharing services sited cost as a reason [5]. As the price of a digital product goes up, users are more willing to try and acquire pirated goods. This relationship may be further strengthened when the user views a product as a necessity and not as a discretionary purchase. Given the importance and consistency of high cost as a factor the drives digital piracy, it was included in the model for completeness.

H16: Perceived cost is positively related to unauthorized downloading intention. 


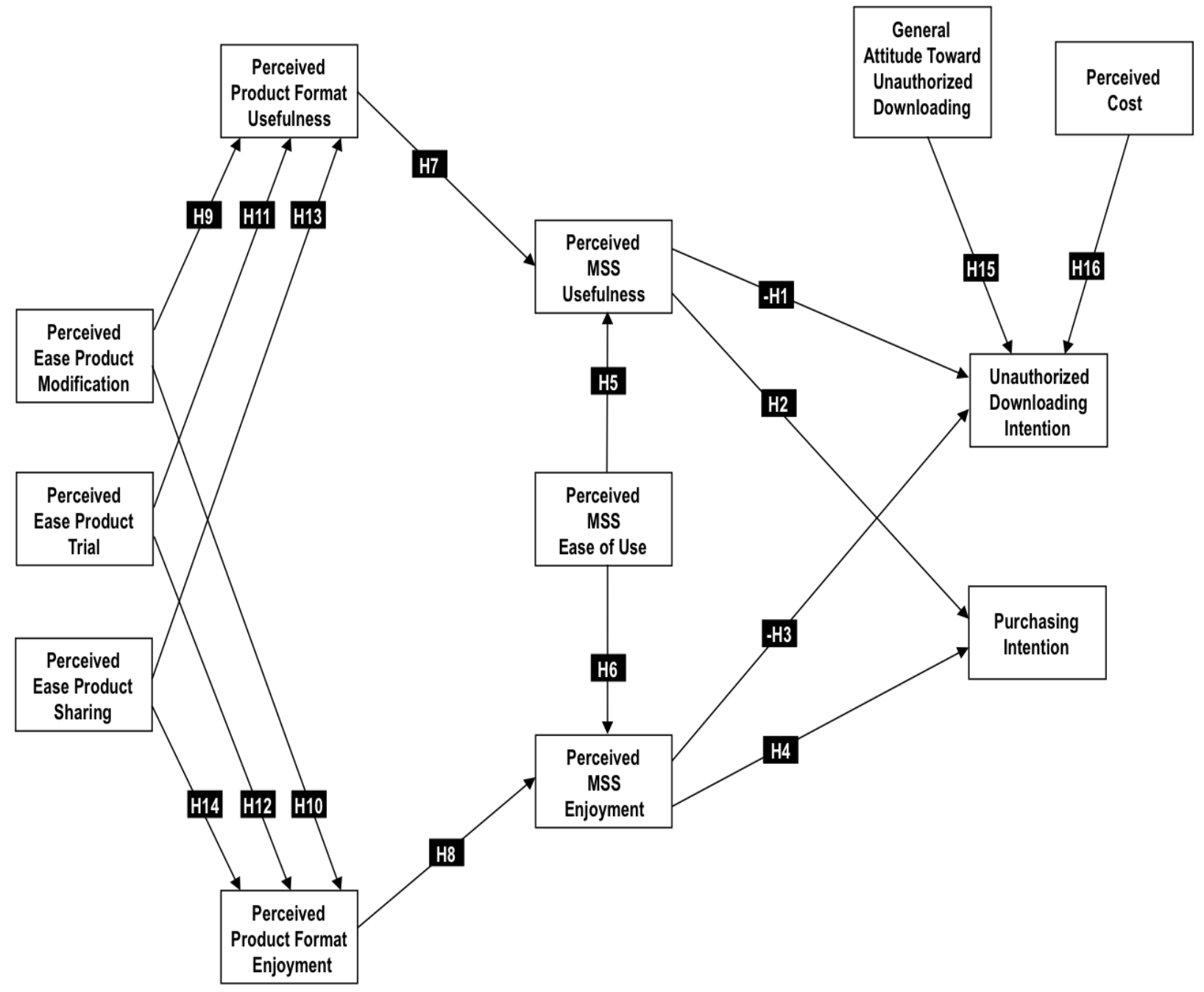

Figure 1: Research model

\section{Methodology}

The research methodology was a quasi experiment using real commercial MSSs. The research design and analytical approach was modeled after studies that examined the impact of website characteristics on behavior [42], [57], [60], [90], [91]. This method is suitable as a way of assessing the initial attitudes that form during the early stages of technology adoption.

The data was collected via an anonymous, self-reported online survey. The measures were adapted from previous studies that examined technology adoption [39] and modified for the specific context of this study. The survey administration was individually randomized for each subject and a response was required for each item. Participation was voluntary and subjects were free to leave the study at any time. Every subject who participated in the study completed every task. There were no missing cases or values.

The sample used for the study was drawn from a highly diverse pool of undergraduate students at a large urban commuter college that was considered among the most diverse in North America. At the time, more than 150 countries were represented at the institution. Approximately $38 \%, 37 \%, 14 \%$, and $11 \%$ of the population were White, Asian, Hispanic, or Black, respectively. Approximately two-thirds of the students were full time. With respect to the sample itself, the mean and median age was 22.1 and 21, respectively, and the standard deviation was 3.34. Ages ranged from 18 to 35 years old. $51 \%$ of the sample was female and $49 \%$ of the sample was male. $93 \%$ of the women and $85 \%$ of the men reported to have engaged in copyright infringement at some point and overall the figure was $89 \% .62 \%$ of the subjects have consumed some form of authorized content. With respect to streams and downloads specifically, $48 \%$ of the women and $41 \%$ of the men reported having purchased music content in this manner. 
These figures can be compared to population characteristics in the United States. The percentage of users who have engaged in some form of copyright infringement by age in years is $53 \%$ for those $16-24,45 \%$ for those $25-34$, $32 \%$ for those $35-44,25 \%$ for those $45-55$, and 18\% for those $55-64$ [48]. Among all users aged $16-64$ years old, $40 \%$ of men and $30 \%$ of women have engaged in copyright infringement [51]. The majority of users aged $15-39$ years old consume some form of authorized content as streams or downloads [50].

The college environment in which the sample was drawn may be a factor that explains higher rates of copyright infringement in the sample compared to the population. As noted in previous studies, the availability to information technology such as computers and broadband on college campuses make it easier to either download or stream content [10]. Furthermore, a social environment in which copyright infringement is prevalent, which is often the case on college campuses, tends to encourage others to adopt similar behaviors [10].

For the purposes of this study, the pool was deemed suitable because students from urban commuter colleges, in contrast to traditional college students, tend to better reflect the general adult population. They tend to be older, more likely to have jobs, and possess more life experience in comparison to traditional college students. Perhaps most importantly, the subject pool was deemed appropriate because college students tend to have experience in acquiring digital products online, both legally and as unauthorized downloads [4]. To confirm subjects were screened to ensure that they had experience consuming music online. Overall, the sample characteristics reflected the population of contemporary music streaming content users [48]. File sharing experience and online music consumption statistics for the sample are noted in Table 2.

As a side note, the use of college students for this type of study is supported by the work of Krawczyk et al. in which they specifically addressed the question of whether both social and ethical norms concerning property rights and online behavior differ between student samples and the broader population [61]. They found that social norms related to online piracy tend to follow similar patterns in student and in other populations. Their research findings suggested that online piracy could be properly studied using student samples.

The subjects were further screened in order to verify that they personally had access to computers that they controlled and that they could freely choose from among different methods of acquiring music online. Subjects were included in the study if they had engaged in any form of music downloading or streaming in the past, legal or otherwise. Responses to screening questions were used to assign subjects to unfamiliar MSSs to shop for unfamiliar music during the course of the study. The purpose was to reduce the effects of prior experience and to encourage an exploration of the MSS features.

After giving their informed consent, subjects were screened and randomly assigned to an unfamiliar commercial MSS in a lab setting. They were given an opportunity to familiarize themselves with the MSS in several ways. Subjects were given the same video demonstration of the site and a written summary highlighting all of the key MSS features and options including platform compatibility, user requirements, portability, sharing methods, playlist options, recommendation tools, navigation features, browsing and search options, and basic music library catalog information. Subjects were informed whether they could also download music files in addition to streaming, the ways in which they could personalize their music experience, and whether music tracks could be modified or repurposed for other projects such as home videos and presentations. They were asked to perform specific tasks regarding various features and subsequently answer questions about those features. The video introduction to the site and the uniform summary of key features served to ensure that each subject received the same set of instructions and in the same manner.

The subjects were also asked to complete a belief elicitation task that entailed finding, sampling, and selecting appropriate music from a collection of unfamiliar music tracks that could be selected and used hypothetically for a friend's birthday celebration. Subjects were screened to ensure that the music was indeed unfamiliar. As part of the belief elicitation task, subjects were told that the music would be used to create a slideshow containing music, photos, and video clips. Subjects were told that in creating these projects, content would be collected, possibly edited and remixed, arranged, and subsequently shared using any programs of their choice. Subjects were told that the music they were searching for was only available for purchase at their assigned MSS. They were told that the music was also available on file-sharing sites. After completing the shopping task, subjects were asked about their experience at the site. The entire process lasted approximately $75-90$ minutes.

The measures used to assess the various constructs in the model were adopted from previous studies that focused on e-commerce technology adoption, tested in a pilot study, and then modified and refined for the specific context of this research. The complete list of measures is provided in Appendix A. A panel of experts assessed the language associated with the instructions, questionnaire, and scenario. Negative terms such as piracy, unauthorized, and illegal were avoided to the extent possible in order to diminish potential bias. Convergent validity, divergent validity, and reliability were assessed statistically and are discussed in the results and analysis section below. 
The MSSs used in this quasi experiment were those developed by Grooveshark and Rhapsody, the latter of which is now known as Napster. Rhapsody has since grown to become a popular streaming service that offers access to one of the largest libraries of music online. Grooveshark ceased operations in 2015. Both sites were selected because they were fully operational sites and representative of MSSs that allowed for an evaluation of the theoretical model that could be generalized. In this regard, it was important to use fully functional sites that would allow the subjects to browse through manifold product options and experience different music streaming possibilities. The two MSSs used in the study were also selected because they were relevant to the sample so the subjects would be more engaged in the tasks assigned to them. Furthermore, a pilot study indicated that subjects tended to be unfamiliar with one or both MSSs and this facilitated the assignment of a subject to an unfamiliar MSS. As noted previously, this was necessary in order to reduce the effects of prior experience. The need to assign subjects to unfamiliar MSSs was one of the main reasons that more popular MSSs such as Spotify was not used in the study.

Each MSS used in the study had a contrasting design esthetic. With respect to the user interface, Grooveshark employed a clean, minimalist design while Rhapsody used a more detailed user interface that included information on things such as music trends and new releases. The two sites implemented various features in different ways. Users could browse for music or search using different criteria. Both sites included a personal music library that could be customized, recommendation tools, browser and app-based music players, the ability to create playlists, and the ability to share music. Users could tag favorite tracks and review their listening history. An inspection of the MSSs showed that they provided enough variance in the measures among the subjects for an adequate test of the theoretical model.

Both sites used in this study allowed users to create a personalized listening experience, based on music and listening preferences. The design of the Grooveshark interface was simple and minimalist in comparison to Rhapsody, the latter of which included additional content such as music blogs, band history, news, artist features, and charting information. At the time of the data collection, Grooveshark offered music in the form of streaming exclusively whereas Rhapsody offered streaming and downloadable content. Rhapsody generated revenue through advertising, subscription fees, and also through a linked sister site that allowed users to purchase mp3 downloads. Grooveshark generated revenue through advertising and subscription fees. One of the goals in choosing very different types of MSSs in terms of style, esthetics, and implementation was to expose users to a greater range of user experiences, increase variation in the data set, and elicit a wider range of user responses.

\section{Results and Analysis}

Partial least squares structural equation modeling (PLS-SEM) was used to analyze the data. The analysis tool was SmartPLS version 3.2.6. The procedure has certain advantages over other methods. It does not have strict normality requirements, which gives the researcher some flexibility with respect to the data set [6], [15], [123]. The technique is well suited for testing complex relationships since it avoids inadmissible solutions and factor indeterminacy that can result from models with large numbers of variables, relationships, and moderating effects [91]. An important advantage of PLS-SEM is that the sample size requirements are relatively small allowing the investigator to economize on time and expense.

To determine the minimum required sample size, a rule of thumb is to consider the latent construct with the most causal relationships and the indicator block with the largest number of indicators. The larger number multiplied by ten determines the minimum sample size [15]. In this study, unauthorized downloading intention was the latent construct with the greatest number of causal relationships, which were four. The indicator block associated with perceived product format usefulness had the largest number of indicators, which totaled seven. (One item was dropped from the final analysis.) As a result, the required minimum number of samples was 70 . This study included 139 cases, which substantially exceeded the minimum required sample size.

Table 2 below summarizes key characteristics of the sample, including self-reported file sharing habits and music consumption. Among the participants in this study, $62 \%$ have acquired authorized music online from sources such as Amazon and Apple iTunes in the past. P2P file sharing experience was highly prevalent among the subjects with $89 \%$ reporting having engaged in some form of P2P file sharing. Several reported having substantial libraries of unauthorized music on their computers with a median of 225 music tracks.

Common methods bias was examined and assessed using Harman's one factor test [96]. An exploratory factor analysis including all the factors was conducted and no single dominant factor emerged from the unrotated factor solutions nor did the first factor in a principal components analysis explain the majority of the variance in the variables [96]. In addition, the correlation matrix did not exhibit high correlations between constructs, generally viewed as those above a value of 0.90 [91]. Therefore, one can reasonably exclude the possibility of common methods bias.

Multicolinearity was assessed by calculating variance inflation factors (VIF) for each set of the latent variable indicators. They are presented in Table 5. When indicators correlate too highly with each other determining the significance of a model becomes more difficult and cannot be reliably interpreted. Multicolinearity is indicated when 
VIFs exceed 5.0 according to Hair et al. [38]. Others suggest that VIF should not exceed 10.0 [12]. In this study none of the indicators exceeded 5.0 and thus multicolinearity issues were not manifest.

\subsection{Measurement Model Assessment}

Item reliability and internal consistency were assessed according to common practice [6], [15], [123]. After an initial analysis, six measurement items were dropped because of low loading on their respective factors or because they loaded more highly on factors other than the ones they were intended to measure. The dropped items excluded from further analysis were PEPM3, PMUA1, PMUA6, and PPFU4. The results from the subsequent analysis were reasonably good. As noted in Table 6, each item loaded highly on its latent construct. Each item had significant tvalues. As indicated in Table 4, the average variance extracted (AVE) exceeded 0.50 for all constructs, which supports the convergent validity of the constructs. Cronbach's alpha was well above the generally recommended value of 0.70 for all constructs. The composite reliability statistic was above the generally recommended value of 0.70 across the board, which indicated good item reliability.

Discriminant validity of the construct measures was also assessed according to common practice [6], [15], [123] and was found to be satisfactory. As noted in Table 3, the square root of the AVE associated with each construct was greater than the correlations between that construct and others indicating that the construct shares more variance with its own measures. In addition, as noted in Table 6, no item loaded higher on other latent constructs than the construct it was designed to measure. Discriminant validity is further support by the fact that the correlations among all constructs were below the threshold of 0.90 .

\subsection{Structural Model Assessment}

As illustrated in Figure 2, the model was largely supported by the data, with exception of hypothesis H3. Perceived MSS usefulness was found to have a negative relationship with unauthorized downloading intention and a positive relationship purchasing intention ( $B=-0.207, p<0.01$ and $B=0.313, p<0.01$, respectively). The relationship between perceived MSS enjoyment and unauthorized downloading intention was not supported; however, a substantial and significant relationship to purchasing intention was supported $(B=0.420, p<0.01)$. Perceived MSS ease of use was positively linked to perceived MSS usefulness and perceived MSS enjoyment $(B=0.148, p<0.05$ and $B=0.261, p<0.01$, respectively). The link between perceived product format usefulness was positively linked to perceived MSS usefulness $(B=0.628, p<0.01)$. Perceived product format enjoyment was positively linked to perceived MSS enjoyment $(B=0.578, p<0.01)$. Perceived ease of product modification was positively linked to perceived MSS usefulness and perceived MSS enjoyment $(B=0.456, p<0.01$ and $B=0.378, p<0.01$, respectively). Perceived ease of product trial was positively related to perceived product format usefulness and perceived product format enjoyment $(B=0.216, p<0.05$ and $B=0.264, p<0.01$, respectively). Perceived ease of product sharing was positively related to perceived product format usefulness and perceived product format enjoyment $(B=0.203, p<0.05$ and $B=0.144, p<0.10$, respectively). General attitude toward unauthorized downloading and perceived cost was positively related to unauthorized downloading intention $(B=0.645, p<0.01$ and $B=0.197, p<0.01$, respectively). Overall, the model explained more than $51.3 \%$ of the variation with respect to unauthorized downloading intention and $43.1 \%$ of the variation regarding purchasing intention.

Table 2: Demographic information and music acquisition habits of the sample

\begin{tabular}{|l|l|l|l|l|l|l|}
\hline & & & $\begin{array}{l}\text { Online Music } \\
\text { Purchasing } \\
\text { Experience } \\
\text { Frequency (\%) }\end{array}$ & $\begin{array}{l}\text { P2P File Sharing } \\
\text { Experience } \\
\text { Frequency (\%) }\end{array}$ & $\begin{array}{l}\text { Number of } \\
\text { Authorized Music } \\
\text { Files Owned } \\
\text { Mean / Mdn / SD }\end{array}$ & $\begin{array}{l}\text { Number of } \\
\text { Unauthorized } \\
\text { Mean / Mdn / SD }\end{array}$ \\
\hline Female & $71(51 \%)$ & $21.7 / 21 / 2.78$ & $34(48 \%)$ & $66(93 \%)$ & $290 / 50 / 772$ & $564 / 250 / 843$ \\
\hline Male & $68(49 \%)$ & $22.6 / 21 / 3.79$ & $28(41 \%)$ & $58(85 \%)$ & $348 / 5 / 1354$ & $2423 / 200 / 6937$ \\
\hline Overall & $139(100 \%)$ & $22.1 / 21 / 3.34$ & $62(45 \%)$ & $124(89 \%)$ & $318 / 20 / 1096$ & $453 / 225 / 4959$ \\
\hline
\end{tabular}


Table 3: Construct correlations (Square root AVE in bold)

\begin{tabular}{|l|r|r|r|r|r|r|r|r|r|r|r|l|}
\hline & GATUD & PC & PEPPS & PEPSS & PEPTS & PI & PME & PMEOU & PMU & PPFE & PPFU & UDI \\
\hline GATUD & $\mathbf{0 . 8 8 8}$ & & & & & & & & & & & \\
\hline PC & -0.173 & $\mathbf{0 . 7 3 6}$ & & & & & & & & & & \\
\hline PEPM & -0.090 & -0.033 & $\mathbf{0 . 8 1 2}$ & & & & & & & & & \\
\hline PEPS & -0.077 & 0.245 & 0.345 & $\mathbf{0 . 7 5 4}$ & & & & & & & & \\
\hline PEPT & -0.052 & 0.304 & 0.142 & 0.457 & $\mathbf{0 . 7 3 6}$ & & & & & & & \\
\hline PI & -0.204 & 0.232 & 0.291 & 0.364 & 0.288 & $\mathbf{1 . 0 0 0}$ & & & & & & \\
\hline PME & -0.271 & 0.341 & 0.274 & 0.527 & 0.507 & 0.607 & $\mathbf{0 . 8 1 3}$ & & & & & \\
\hline PMEOU & 0.051 & 0.176 & 0.228 & 0.552 & 0.620 & 0.286 & 0.509 & $\mathbf{0 . 7 4 7}$ & & & & \\
\hline PMU & -0.117 & 0.116 & 0.473 & 0.461 & 0.324 & 0.564 & 0.597 & 0.388 & $\mathbf{0 . 7 7 4}$ & & & \\
\hline PPFE & -0.258 & 0.198 & 0.471 & 0.398 & 0.393 & 0.459 & 0.690 & 0.428 & 0.508 & $\mathbf{0 . 7 9 2}$ & & \\
\hline PPFU & -0.206 & 0.180 & 0.562 & 0.462 & 0.381 & 0.505 & 0.613 & 0.383 & 0.685 & 0.733 & $\mathbf{0 . 7 9 8}$ & \\
\hline UDI & 0.673 & -0.295 & -0.237 & -0.119 & -0.038 & -0.224 & -0.252 & -0.003 & -0.238 & -0.299 & -0.328 & $\mathbf{0 . 8 3 0}$ \\
\hline
\end{tabular}

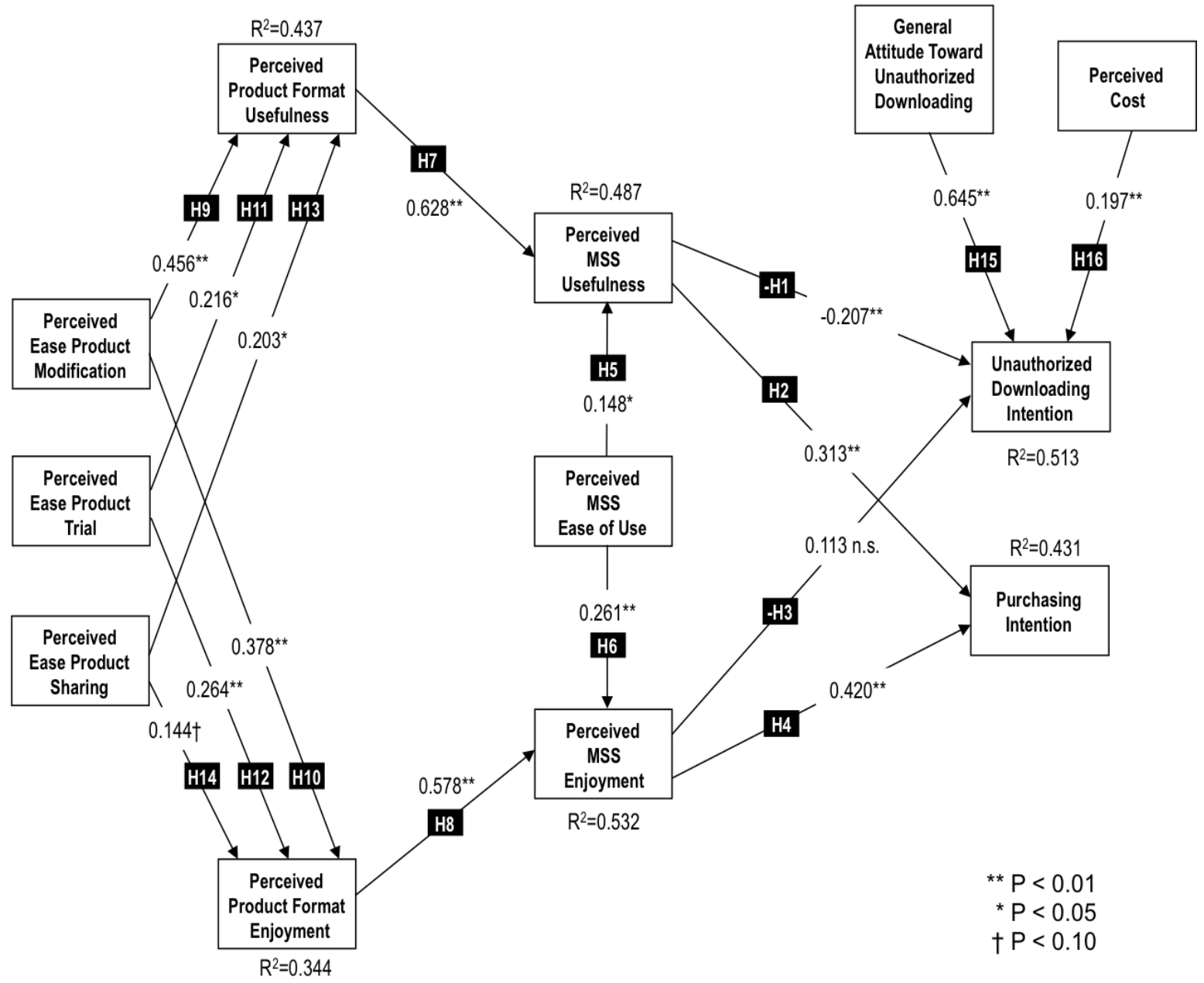

Figure 2: Research model results 
Table 4: Assessment of measurement model

\begin{tabular}{|l|l|l|l|l|l|l|}
\hline & AVE & $\begin{array}{l}\text { Composite } \\
\text { Reliability }\end{array}$ & R Square & $\begin{array}{l}\text { Cronbachs } \\
\text { Alpha }\end{array}$ & Mean & SD \\
\hline GATUD & 0.789 & 0.949 & & 0.933 & 4.529 & 1.548 \\
\hline PC & 0.542 & 0.774 & & 0.724 & 4.193 & 1.312 \\
\hline PEPM & 0.659 & 0.885 & & 0.828 & 3.883 & 1.483 \\
\hline PEPS & 0.568 & 0.866 & & 0.809 & 5.112 & 1.132 \\
\hline PEPT & 0.541 & 0.852 & & 0.783 & 5.663 & 0.996 \\
\hline PI & 1.000 & 1.000 & 0.431 & 1.000 & 4.144 & 1.958 \\
\hline PME & 0.662 & 0.921 & 0.532 & 0.897 & 5.168 & 1.225 \\
\hline PMEOU & 0.559 & 0.861 & & 0.806 & 5.627 & 1.002 \\
\hline PMU & 0.600 & 0.857 & 0.487 & 0.776 & 4.630 & 1.228 \\
\hline PPFE & 0.627 & 0.910 & 0.344 & 0.881 & 4.826 & 1.247 \\
\hline PPFU & 0.637 & 0.913 & 0.437 & 0.886 & 4.630 & 1.268 \\
\hline UDI & 0.689 & 0.869 & 0.513 & 0.774 & 4.572 & 1.665 \\
\hline
\end{tabular}

Table 5: Variance inflation factor results

\begin{tabular}{|c|c|c|c|c|c|c|c|}
\hline \multicolumn{2}{|c|}{$\begin{array}{l}\text { General Attitude } \\
\text { Toward Unauthorized } \\
\text { Downloading }\end{array}$} & \multicolumn{2}{|c|}{$\begin{array}{l}\text { Perceived } \\
\text { Cost }\end{array}$} & \multicolumn{2}{|c|}{$\begin{array}{l}\text { Perceived Ease } \\
\text { Product Modification }\end{array}$} & \multicolumn{2}{|c|}{$\begin{array}{l}\text { Perceived Ease } \\
\text { Product Sharing }\end{array}$} \\
\hline GATUD1 & 4.518 & PC1 & 1.228 & PEPM1 & 1.963 & PEPS1 & 1.931 \\
\hline GATUD2 & 3.782 & PC2 & 1.209 & PEPM2 & 1.899 & PEPS2 & 1.887 \\
\hline GATUD3 & 2.507 & PC3 & 1.263 & PEPM4 & 2.155 & PEPS3 & 1.297 \\
\hline GATUD4 & 2.622 & & & PEPM5 & 1.575 & PEPS4 & 1.383 \\
\hline GATUD5 & 3.699 & & & & & & \\
\hline \multicolumn{2}{|c|}{$\begin{array}{l}\text { Perceived Ease } \\
\text { Product Trial }\end{array}$} & \multicolumn{2}{|c|}{$\begin{array}{l}\text { Purchasing } \\
\text { Intention }\end{array}$} & \multicolumn{2}{|c|}{$\begin{array}{l}\text { Perceived Product } \\
\text { Format Enjoyment }\end{array}$} & \multicolumn{2}{|c|}{$\begin{array}{l}\text { Perceived Product } \\
\text { Format Usefulness }\end{array}$} \\
\hline PEPT1 & 1.763 & $\mathrm{PI}$ & 1.000 & PPFE1 & 2.497 & PPFU1 & 2.128 \\
\hline РEPT2 & 1.211 & & & PPFE2 & 2.136 & PPFU2 & 2.414 \\
\hline РЕPT3 & 1.638 & & & PPFE3 & 2.025 & PPFU3 & 1.937 \\
\hline PEPT4 & 1.677 & & & PPFE4 & 1.984 & PPFU5 & 1.873 \\
\hline \multirow[t]{2}{*}{ PEPT5 } & 1.525 & & & PPFE5 & 1.849 & PPFU6 & 2.390 \\
\hline & & & & PPFE6 & 2.134 & PPFU7 & 2.035 \\
\hline \multicolumn{2}{|c|}{$\begin{array}{l}\text { Perceived MSS } \\
\text { Enjoyment }\end{array}$} & \multicolumn{2}{|c|}{$\begin{array}{l}\text { Perceived MSS } \\
\text { Ease of Use }\end{array}$} & \multicolumn{2}{|c|}{$\begin{array}{l}\text { Perceived MSS } \\
\text { Usefulness }\end{array}$} & \multicolumn{2}{|c|}{$\begin{array}{l}\text { Unauthorized } \\
\text { Downloading } \\
\text { Intention }\end{array}$} \\
\hline PME1 & 2.544 & PMEOU1 & 1.594 & PMUA2 & 1.367 & UDI1 & 1.451 \\
\hline PME2 & 2.304 & PMEOU2 & 1.732 & PMUA3 & 1.916 & UDI2 & 1.761 \\
\hline PME3 & 1.744 & PMEOU3 & 1.276 & PMUA4 & 1.438 & UDI3 & 1.668 \\
\hline PME4 & 3.315 & PMEOU4 & 1.655 & PMUA5 & 1.696 & & \\
\hline PME5 & 2.553 & PMEOU5 & 2.115 & & & & \\
\hline PME6 & 2.508 & & & & & & \\
\hline
\end{tabular}


Table 6: Cross loadings

\begin{tabular}{|c|c|c|c|c|c|c|c|c|c|c|c|c|}
\hline & GATUD & PC & PEPM & PEPS & PEPT & PI & PME & PMEOU & PMU & PPFE & PPFU & UDI \\
\hline GATUD1 & 0.926 & -0.180 & -0.047 & -0.061 & -0.047 & -0.169 & -0.250 & 0.094 & -0.073 & -0.240 & -0.196 & 0.641 \\
\hline GATUD2 & 0.906 & -0.195 & -0.044 & -0.021 & -0.039 & -0.159 & -0.230 & 0.077 & -0.104 & -0.232 & -0.159 & 0.626 \\
\hline GATUD3 & 0.847 & -0.141 & -0.077 & -0.099 & -0.105 & -0.224 & -0.241 & 0.030 & -0.061 & -0.220 & -0.158 & 0.549 \\
\hline GATUD4 & 0.849 & -0.133 & -0.162 & -0.111 & -0.060 & -0.186 & -0.240 & -0.050 & -0.149 & -0.275 & -0.220 & 0.509 \\
\hline GATUD5 & 0.909 & -0.118 & -0.087 & -0.062 & 0.006 & -0.178 & -0.245 & 0.053 & -0.136 & -0.190 & -0.189 & 0.645 \\
\hline PC1 & -0.094 & 0.645 & 0.108 & 0.286 & 0.267 & 0.203 & 0.192 & 0.256 & 0.103 & 0.213 & 0.218 & -0.128 \\
\hline PC2 & -0.026 & 0.601 & -0.034 & 0.070 & 0.172 & 0.116 & 0.144 & 0.034 & -0.001 & 0.099 & 0.126 & -0.108 \\
\hline PC3 & -0.194 & 0.922 & -0.077 & 0.200 & 0.256 & 0.201 & 0.346 & 0.130 & 0.120 & 0.155 & 0.119 & -0.320 \\
\hline PEPM1 & -0.089 & -0.033 & 0.837 & 0.284 & 0.058 & 0.297 & 0.219 & 0.147 & 0.390 & 0.415 & 0.459 & -0.243 \\
\hline PEPM2 & .008 & -0.042 & 804 & 0.274 & 0.174 & 0.205 & 0.225 & 0.274 & 0.429 & 0.347 & 0.369 & -0.107 \\
\hline PEPM4 & -0.094 & -0.009 & 0.868 & 0.330 & 0.128 & $\mid 0.272$ & 0.267 & 0.182 & 0.443 & 0.446 & 0.570 & -0.216 \\
\hline PEPM5 & -0.109 & -0.029 & 731 & 0.218 & 0.114 & 0.146 & 0.166 & 0.152 & 0.256 & 0.297 & 0.390 & -0.189 \\
\hline PEPS1 & 115 & 0.221 & 284 & 0.820 & 0.352 & 0.268 & 0.387 & 0.461 & 0.356 & 0.291 & 0.366 & -0.104 \\
\hline PEPS2 & 005 & 0.113 & 0.274 & 0.824 & 412 & .368 & 493 & 0.514 & 0.390 & 0.341 & 0.394 & -0.025 \\
\hline PEPS3 & 45 & 0.236 & 0.050 & 0.583 & 0.262 & 0.230 & 0.395 & 0.238 & 0.157 & 0.241 & 0.150 & -0.028 \\
\hline PEPS4 & 052 & 0.129 & 0.383 & 0.728 & .294 & 0.18 & 0.290 & 0.272 & 0.442 & 0.336 & 0.418 & 0.165 \\
\hline PEPS5 & -0.078 & 0.280 & 0.216 & 0.787 & 0.393 & 0.329 & 0.453 & 0.569 & 0.310 & 0.271 & 0.336 & -0.105 \\
\hline PEPT1 & 27 & 0.328 & 134 & 0.329 & 806 & 271 & 455 & 513 & 0.318 & 0.309 & 0.297 & .000 \\
\hline PEPT2 & 0.017 & 0.212 & -0.085 & 0.131 & 502 & 0.028 & 0.171 & 0.279 & -0.014 & 0.170 & 0.135 & 0.054 \\
\hline PEPT3 & 25 & 0.149 & 0.099 & 0.424 & 781 & 208 & 410 & 612 & 0.291 & 307 & 309 & 0.071 \\
\hline PEPT4 & -0.047 & 0.217 & 0.112 & 0.342 & 804 & 0.295 & 0.462 & 0.406 & 0.316 & 0.342 & 0.337 & -0.006 \\
\hline PEPT5 & -0.050 & 0.234 & 0.187 & 0.393 & 0.740 & 年 & 0.290 & 0.433 & 0.164 & 0.283 & 0.274 & -0.084 \\
\hline PI & -0.204 & 0.232 & 0.291 & 0.364 & 0.288 & 1.000 & 0.607 & 0.286 & 0.564 & 459 & 0.505 & -0.224 \\
\hline PME1 & $-0 .<10$ & 0.299 & 0.268 & 0.465 & 0.499 & 0.500 & 0.850 & 0.540 & 0.534 & 0.605 & 0.575 & -0.228 \\
\hline PME2 & -0.247 & 0.209 & 0.310 & 0.457 & 0.261 & 0.576 & 0.822 & 0.325 & 0.541 & 588 & 529 & -0.316 \\
\hline PME & -0.150 & 0.370 & 0.082 & 0.365 & 0.493 & $0.4<0$ & 0.727 & 0.389 & 0.358 & 0.501 & 0.391 & 0.111 \\
\hline PME4 & 92 & 0.301 & 0.234 & 0.384 & 395 & 0.419 & 0.864 & 0.451 & 0.437 & .584 & 487 & -0.240 \\
\hline PME & -0.118 & 0.220 & 0.258 & 557 & 443 & 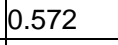 & 829 & 479 & 0.604 & 555 & 0.603 & 0.105 \\
\hline PME6 & 11 & 0.292 & 0. & 0.307 & 02 & 0.001 & 0.781 & 0.268 & 0.398 & 524 & 0.363 & -0.216 \\
\hline PMEOU1 & 0.062 & 0.154 & 0.187 & 0.410 & 0.402 & 0.277 & 0.397 & 0.772 & 0.299 & 0.366 & 0.320 & 0.051 \\
\hline PME & 0.048 & 0.212 & 0 & 94 & 75 & 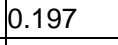 & 286 & 731 & 0.201 & 0.210 & 0.181 & 0.038 \\
\hline PMEOU3 & -0.085 & 0.109 & -0.017 & 0.257 & 0.383 & 0.045 & 0.270 & 0.543 & 0.015 & 0.244 & 0.084 & 0.013 \\
\hline PM & 0.055 & 0.122 & 0.256 & 0.483 & 598 & 0.283 & 501 & 0.829 & 0.461 & 0.439 & 0.424 & -0.073 \\
\hline PMEC & 10 & 91 & 0.196 & 0.466 & 0.508 & 0.168 & 0.367 & 0.825 & 0.274 & 0.264 & 0.267 & 0.008 \\
\hline
\end{tabular}




\begin{tabular}{|c|c|c|c|c|c|c|c|c|c|c|c|c|}
\hline PMUA2 & -0.178 & 0.159 & 0.269 & 0.249 & 0.202 & 0.480 & 0.449 & 0.226 & 0.716 & 0.347 & 0.409 & -0.276 \\
\hline PMUA3 & -0.077 & 0.045 & 0.421 & 0.346 & 0.095 & 0.438 & 0.478 & 0.171 & 0.829 & 0.422 & 0.566 & -0.162 \\
\hline PMUA4 & -0.005 & 0.136 & 0.404 & 0.484 & 0.474 & 0.434 & 0.485 & 0.529 & 0.771 & 0.393 & 0.584 & -0.129 \\
\hline PMUA5 & -0.114 & 0.019 & 0.363 & 0.329 & 0.209 & 0.394 & 0.433 & 0.252 & 0.777 & 0.409 & 0.549 & -0.179 \\
\hline PPFE1 & -0.136 & 0.063 & 0.485 & 0.411 & 0.335 & 0.395 & 0.515 & 0.437 & 0.537 & 0.848 & 0.706 & -0.215 \\
\hline PPFE2 & -0.222 & 0.096 & 0.461 & 0.279 & 0.216 & 0.433 & 0.533 & 0.228 & 0.519 & 0.785 & 0.700 & -0.270 \\
\hline PPFE3 & -0.229 & 0.210 & 0.227 & 0.315 & 0.358 & 0.287 & 0.586 & 0.344 & 0.287 & 0.779 & 0.483 & -0.203 \\
\hline PPFE4 & -0.263 & 0.246 & 0.308 & 0.301 & 0.393 & 0.409 & 0.630 & 0.357 & 0.361 & 0.787 & 0.513 & -0.275 \\
\hline PPFE5 & -0.147 & 0.074 & 0.404 & 0.332 & 0.251 & 0.336 & 0.460 & 0.331 & 0.394 & 0.743 & 0.544 & -0.228 \\
\hline PPFE6 & -0.227 & 0.247 & 0.354 & 0.247 & 0.303 & 0.313 & 0.546 & 0.331 & 0.309 & 0.806 & 0.528 & -0.228 \\
\hline PPFU1 & -0.172 & 0.263 & 0.513 & 0.393 & 0.395 & 0.362 & 0.567 & 0.386 & 0.475 & 0.741 & 0.781 & -0.268 \\
\hline PPFU2 & -0.169 & 0.160 & 0.458 & 0.402 & 0.309 & 0.421 & 0.463 & 0.300 & 0.673 & 0.514 & 0.849 & -0.264 \\
\hline PPFU3 & -0.127 & 0.147 & 0.353 & 0.317 & 0.312 & 0.432 & 0.458 & 0.405 & 0.509 & 0.540 & 0.768 & -0.259 \\
\hline PPFU5 & -0.133 & 0.034 & 0.443 & 0.368 & 0.283 & 0.425 & 0.466 & 0.229 & 0.567 & 0.514 & 0.770 & -0.219 \\
\hline PPFU6 & -0.214 & 0.121 & 0.535 & 0.391 & 0.299 & 0.406 & 0.490 & 0.246 & 0.481 & 0.652 & 0.822 & -0.298 \\
\hline PPFU7 & -0.172 & 0.134 & 0.376 & 0.331 & 0.224 & 0.375 & 0.495 & 0.279 & 0.557 & 0.552 & 0.796 & -0.264 \\
\hline UDI1 & 0.593 & -0.223 & -0.183 & -0.088 & 0.007 & -0.151 & -0.178 & -0.009 & -0.152 & -0.218 & -0.189 & 0.808 \\
\hline UDI2 & 0.539 & -0.283 & -0.102 & -0.024 & -0.057 & -0.172 & -0.184 & 0.034 & -0.190 & -0.244 & -0.241 & 0.850 \\
\hline UDI3 & 0.540 & -0.228 & -0.308 & -0.186 & -0.045 & -0.237 & -0.267 & -0.032 & -0.253 & -0.284 & -0.389 & 0.831 \\
\hline
\end{tabular}

\section{Discussion}

As noted in the introduction, users increasingly demonstrate a willingness to forgo the ownership of physical media and digital files. Instead, they are becoming comfortable with having access to music and other types of content and they are willing to pay subscription fees, rental fees, or consume advertising. This access economy business model allows users to avoid many of the issues associated with ownership. This embrace of the model for music consumption is reflected in statistics that show the adoption of MSSs has continued to rise [92] with 90 million subscribers as of 2016 [100].

It is clear that the access economy business model has significant market appeal and this can be attributed to the digital technologies that make consumption platforms and manifold value propositions possible. It is not clear, however, what specific features appeal most to users and to what extent. This research was an initial exploration of the drivers of MSS adoption and attempted to provide a better understanding of key MSS attributes and MPURs. This focus on MPURs in particular is relatively novel and largely unexamined in the literature.

It is also clear that digital piracy remains an issue for artists and PROs. Levels of digital piracy remain high and continues largely unabated. However, what seems to be changing is the nature of digital piracy. Many users are adopting stream ripping or they are using private networks to exchange files in order to hide illicit activity. Developing effective strategic responses remains a challenge. A relatively novel approach examined in this research considers the influence MSS attributes and MPURs on digital piracy. It is an approach that calls for a focus on the design of MSSs in order to better address digital piracy.

\subsection{Influence of Perceived Usefulness, Enjoyment, and Ease of Use}

The results of the empirically tested model support five of the first six hypotheses examined in this study. The effects were significant and substantial. A MSS that is perceived to be useful and enjoyable is positively related to the purchasing intention of a MSS. In other words, a MSS that provides utility to the user and is fun to use will encourage system adoption. In order for a system to be useful and enjoyable, it must also be easy to use. Furthermore, the 
perceived usefulness of a MSS was negatively related to unauthorized downloading intention. This result supports the notion that developing well-designed MSSs that help users satisfy their needs with respect to the many different facets of music consumption is an effective strategy to help reduce digital piracy.

Surprisingly, the anticipated negative relationship between perceived enjoyment of a MSS and the intention to engage in digital piracy was not supported. This result warrants further investigation in future studies. One possible explanation for this outcome could be that a fun to use MSS may increase overall user excitement and interest in music more generally. The discovery of interesting new artists and content could further stimulate a user's appetite for even more content. This could generate a desire to explore different channels including those that are unauthorized and illegal. It is also possible that users who enjoy using MSSs also learn to enjoy and become proficient in using stream-ripping tools and file-sharing networks.

The results of this study should motivate the design and inclusion of specific system features. A MSS should perhaps incorporate easy to use features that enable users to discover new music, learn about artists, organize music collections, create playlists, and share music. The ability to discover new music is essential to users and there are different ways in which this can be realized [26], [58]. The discovery of music can be supported by well-defined and detailed music categories that are easy to browse. It can be achieved with quality algorithms that generate automatic playlists based on user listening history, mood, or preferences.

User preferences vary substantially. Some may have deep conscious insight regarding their personal choices and may thus do better with a discovery system that provides detailed information within their preferred genre while others may have a diversity of interests and therefore prefer discovery tools that allow exposure to a wider variety of genres and styles [116]. Other users may have a high degree of openness to different genres and music styles and therefore seek novelty through exposure to unfamiliar artists and genres [116] and therefore automatic playlists should be readily available yet easily tailored to personal tastes.

Many of the same features that make MSSs useful can also contribute toward the enjoyment of a system. Offering large music libraries with excellent search tools and recommendation features can lead to the joy of discovery and collection. Tools and features that allow users to create and share playlists can support creativity and community building. A MSS that provides background information about an artist can be not just useful, but also fun to read. One of the challenges of maintaining a large music collection is organizing and searching for titles, but that can be facilitated with the right set of tools, which adds to MSS usefulness and enjoyment.

MSSs can also be perceived as useful and enjoyable if they help users avoid many of downsides to pirating music. For example, pirating files from P2P networks, disk drives, or DVDs can be time consuming and expose users to risks that include legal consequences. The process of illegally downloading music can leave users vulnerable to hacking, viruses, and malware, which is a concern among some users [134]. When sourcing music through piracy, it can be difficult and laborious to find obscure music. File quality of pirated works can vary and be unacceptably poor. The quality of a ripped music track is limited by the original quality of the stream, which is often compressed to optimize transmission rates and reduce latency.

As previously noted, the results also suggest that for a system to be perceived as both useful and enjoyable it should be easy to use. This anticipated finding was consistent with many previous technology adoption studies and so the real issue is how to design for MSS ease of use. There are several possible considerations. A non-intuitive MSS that requires too many steps to accomplish tasks, has a complicated menu structure or poor navigation and search tools, does not integrate well with other systems, or has strict software and hardware requirements could make a MSS substantially more difficult to use. Selecting a MSS should not force the user to make too many tradeoffs that limit both platform options and a personalized user experience. MSSs that make it difficult for users to access content from multiple devices or different locations, requires frequent account verification, or forces users to consume excessive advertising could make a MSS more difficult to use.

\subsection{Influence of Perceived Product Format Usefulness and Enjoyment}

Hypotheses 7 and 8 concern some of the additional ways in which perceived MSS usefulness and perceived MSS enjoyment can be influenced. Specifically, the results show that the perceived product format usefulness and perceived product format enjoyment are indeed important influential factors. Product formats vary substantially in terms of sound quality, file size, digital rights management features, and the extent to which the encoding facilitates various forms of consumption.

The product format can also affect mobility and determine the extent to which users can consume music on the go. The encoding of a streaming file can influence how well the stream performs under different levels of congestion. The product format can determine the range of platforms available for consumption and the extent to which a product can be repurposed. Repurposing a product can include various possibilities such as creating home videos, remixing, sampling, or incorporating into multimedia projects. 
Some MSSs allow users to download a file to facilitate mobile consumption offline, but often the files are encoded with digital rights management features that restrict other uses such as sharing, modification, and sound sampling. The next set of hypotheses address a specific set of MPURs than can be associated with a product format.

\subsection{Influence of Perceived Ease of Modification, Trial, and Sharing}

Hypotheses 9 - 14 addressed a specific set of MPURs that relate to ease of product modification, perceived ease of product trial, and perceived ease of product sharing. All were found to influence perceived product format usefulness and perceived product format enjoyment. The importance of product modification reflects user expectations to be able to easily alter and transform digital products. The need for this may be due to a variety of reasons. For one, the desire for easy to modify products may be motivated by social media, which encourages users to share and express ideas and opinions related to art, culture, society, science, economics, or politics often in the form of memes and mashups. The availability and proliferation of audio and video recording devices allow users to readily capture or access content from many different sources. Content can then be modified with increasingly inexpensive, easy to use editing tools. This allows the average user to experiment with ideas through various product transformations.

The perceived ease of product modification may be important to users for more basic reasons. A simple product modification such as a file format conversion may be needed to enable consumption on different types of platforms. In some cases, the compression of a digital product, which entails a transformation of the digital encoding, may be necessary in order to facilitate transmission over a crowded network. A product transformation could also be necessary in order to repurpose a product. For example, sometimes music products are modified in order to create new types of products such as ringtones.

The results of this research also suggest that the ease of product trial, which is the ability to check out and assess digital music, is important to users. Indeed, a frustration for many users during the heyday of radio, CDs, and vinyl was the inability to easily access and listen to unfamiliar music before making a purchasing decision. At any given time, only a very small percentage of available music could be consumed on broadcast radio. Playlists were usually not known to the public ahead of time. CDs were expensive, and to discourage piracy, users were usually not permitted to return unsealed products even if they were unsatisfied with their purchase. MSSs make it easy for the user to check out a wide range of music content while essentially eliminating the risk of any buyer's remorse.

During the first big wave of P2P file-sharing in the early 2000s when digital piracy increased dramatically, it was never really clear to what extent users were involved in the process as an act of community engagement and motivated by reciprocity. Many believe that users were primarily motivated by self-interest and did not really care if it was theft from PROs and artists. We do know that music sharing is often done to express ideas, sentiments, and emotion. Music can be incorporated into user-generated videos for those same purposes. Sharing invites commitment and can lead to a sense of community. The results of this study support the notion that sharing is important to users.

There are several ways that sharing can be facilitated and it can be done in ways that protects the rights of the PRO. A PRO could allow users to share files objects such as mp3 file with DRM tools to govern what can be shared, with whom, and for how long. Or instead of using file objects, PROs can incorporate sharing in MSSs by enabling the easy sharing of links to content. The PRO could decide whether the links can be shared with other users of a particular MSS or if it can be shared with the general public.

\subsection{Influence of Product Cost}

Hypothesis 15 addressed the issue of cost and the results affirmed that it is an important consideration for users. Consistent with numerous studies, the high price of a digital good can motivate users to engage in digital piracy [10], [67], [106]. PROs therefore do have to price products appropriately. The price for electronics has declined substantially over the years, but the price for music on physical media had been relatively slow to follow the same trend. It is difficult to compete with free, but the results of this study suggest that a competitively priced product can have a substantial influence on user attitudes.

The relatively low price for streaming content represents a substantial reduction in the cost of music when compared to CDs and other physical media. The monthly subscription fee is roughly equivalent to the price of a single CD in the United States. For the price, MSSs offer users access to libraries containing millions of tracks and for most this represents a good bargain. But it is important to note that there are different models for pricing streaming content. Weijters et al. found that users prefer legal and ethical options, but favor different ways of paying for content [130]. Older users tend to prefer paying subscription fees while younger users prefer to consume advertising [130]. 


\subsection{Influence of General Attitude Toward Digital Piracy}

Hypothesis 16 concerned the influence of the user's preexisting general attitude toward digital piracy. Users develop their overall general attitude toward piracy over time and can result from many different factors including social norms [9], [10], [67], [79], [125], [135], [140], habit [84], [140], and moral and ethical considerations [14], [18], [59], [121], [132], [140]. The study affirmed that an established attitude toward digital piracy is a major factor that influences pirating behavior. Given that general attitudes toward digital piracy develop over time, a short one-time interaction with an attractive and legitimate alternative such as Napster and Grooveshark may not substantially change user views regarding digital piracy. However, over time, and after repeated interactions, the outcome may be different. As MSSs evolve and become more familiar and useful, repeated exposure and use of these systems may persuade users to change their overall attitudes toward digital piracy.

To reiterate and for additional emphasis, in this study, general attitude refers to a user's overall disposition toward digital piracy. It is distinct from the construct that is usually a part of the TAM, which posits that perceived usefulness, perceived enjoyment, and perceived ease of use influence attitude toward a behavior. In turn attitude toward a behavior, perceived social norms, and perceived behavioral control influences behavioral intention and actual behavior. In the TAM, attitude is defined by the immediate context and is local. This variable was not included in the model for the sake of simplicity. Instead, general attitude toward digital piracy was included and refers to the broader context of digital piracy.

\section{Conclusion}

MSSs are an example of the access economy business model. They allow PROs to tailor value propositions with a great deal of precision through software and hardware design. It is possible to define very specific MPURs for a music product and allow for the liberal use of a product or an experience that is too restrictive. Some MPURs may be very relevant and expected by most users while the absence of certain MPURs may not be very noticeable to users. A particular set of MPURs may be similar or depart substantially from traditional usage expectations generally associated with the consumption of music.

This research used as a basis the TAM and addressed how MPURs with respect to modification, trial, and sharing influence MSS adoption and digital piracy. The model proved to be valid, explained a substantial amount of variation, and affirmed the need to address MSSs in terms of MPURs. The results provide guidance for the design and deployment of MSSs in terms of relevant features. The results of this research can be summarized as follows.

1) Perceived MSS ease of use is positively related to perceived MSS usefulness and perceived MSS enjoyment.

2) Perceived MSS usefulness and perceived MSS enjoyment are both positively related to the intention to purchase a MSS.

3) Perceived product format usefulness and perceived product format enjoyment positively influence perceived MSS usefulness and perceived MSS enjoyment, respectively.

4) Perceived MSS usefulness is positively related to purchasing intention and negatively related to unauthorized downloading intention.

5) Perceived MSS enjoyment is positively related to purchasing intention.

6) Perceived ease of product modification, perceived ease of product trial, and perceived ease of product sharing are essential MPURs that are ultimately positively related to MSS adoption and negatively related to the intention to engage in digital piracy.

The results above provide a framework that can be used to design effective MSSs that appeal to users. The results suggest that MSSs can be designed in ways that can steer users away from digital piracy.

\subsection{Limitations}

This study has important limitations that should be taken into account. First, quasi experiments do not offer the degree of internal validity that can be achieved with true experiments. Second, a quasi-experiment examines and measures only reactions and behavioral intentions that are subject to conditions at a particular point in time and not those that evolve over time. Third, this study measured self-reported intention and not actual behavior. The fourth limitation concerns the subject pool. Even though the subject pool used in this study was deemed appropriate, caution should be exercised when attempting to generalize the results of this study to all demographic segments. 


\subsection{Future Research}

The access economy business model is being increasingly applied to music and many other types of digital products. It is important to understand how features and MPURs, whether deliberately defined or as a design byproduct, influence perceived usefulness, enjoyment, adoption, and digital piracy. This is especially important since attitudes toward ownership seem to be evolving. This study highlighted numerous other MPURs that could be examined in future studies.

Another step to advance this research is a longitudinal field study to assess how subjects actually behave over time. Once users adopt a MSS do they remain committed users? As they embrace MSSs to what extent does digital piracy become less attractive? Are some types of MSSs more appealing than others? Do the findings associated with MSSs also translate to other types of streaming and downloading systems that offer movies, books, games, and software? The results of the study, which demonstrate the relevance of usefulness and enjoyment, as a function of modification, trial, and sharing usage rights presents us with a basis to further explore additional factors that influence behavior with respect to MSS adoption and digital piracy.

The negative relationship between perceived MSS enjoyment and unauthorized downloading enjoyment was not supported. This unanticipated outcome was quite surprising, but may have an explanation that warrants future investigation. It could be the case that the enjoyment of a MSS system arouses a sense of excitement over music consumption in general. MSSs that make it easy to explore and discover new music may encourage users to find new music in other channels whether they are legal or not. Another possibility could be related to the fact that MSSs are similar to unauthorized downloading systems in some respects. As users become comfortable and enjoy using MSSs they might also become comfortable and enjoy unauthorized downloading systems as well. These suppositions need to be tested. If true that could mean that in order to discourage digital piracy, PROs need to focus on system utility rather than system enjoyment.

Finally, future studies should attempt to examine the factors that determine MSS adoption and digital piracy for other demographic segments and cultural contexts. Even though the subject pool for this study was deemed to be appropriate for testing the theoretical model, we cannot know with a high degree of certainty if it would apply to other demographic and cultural contexts without further research.

\section{References}

[1] L. Aguiar, Let the music play? Free streaming and its effects on digital music consumption, Information Economics and Policy, vol. 41, pp. 1-14, 2017.

[2] L. Aguiar and B. Martens, Digital music consumption on the internet: Evidence from clickstream data, Information Economics and Policy, vol. 34, pp. 27-43, 2016.

[3] Y. Akbulut, Exploration of the antecedents of digital piracy through a structural equation model, Computers \& Education, vol. 78, pp. 294-305, 2014.

[4] S. Al-Rafee and T. Cronan, Digital piracy: Factors that influence attitude toward behavior, Journal of Business Ethics, vol. 63, no. 3, pp. 237-259, 2006.

[5] AudienceProject, Insights 2017 - Traditional TV \& Streaming in the Nordics, UK \& US, 2017.

[6] D. Barclay, R. Thompson and C. Higgins, The partial least squares (PLS) approach to causal modeling: Personal computer adoption and use as an illustration, Technology Studies, vol. 2, no. 2, pp. 285-309, 1995.

[7] M. T. Bender and Y. Wang, The impact of digital piracy on music sales: A cross-country analysis, International Social Science Review, vol. 84, no. 3/4, pp. 157-170, 2009.

[8] S. Bhattacharjee, R. D. Gopal and G. L. Sanders, Digital music and online sharing: Software piracy 2.0?, Association for Computing Machinery, Communications of the ACM, vol. 46, no. 7, p. 107, 2003.

[9] R. H. Blake and E. S. Kyper, An investigation of the intention to share media files over peer-to-peer networks, Behaviour \& Information Technology, vol. 32, no. 4, pp. 410-422, 2013.

[10] K. Borja, S. Dieringer, and J. Daw, The effect of music streaming services on music piracy among college students, Computers in Human Behavior, vol. 45, pp. 69-76, 2015.

[11] R. Botsman and R. Rogers, What's Mine is Yours: The Rise of Collaborative Consumption. New York: Harper Business, 2010.

[12] B. L. Bowerman and R. O'Connell, Linear statistical models: An applied approach, 2nd ed. Belmont, CA: Duxbury Press, 2000.

[13] R. Casidy, I. Phau and M. Lwin, Religiosity and digital piracy: An empirical examination, Services Marketing Quarterly, vol. 37, no. 1, pp. 1-13, 2016.

[14] L. Cesareo and A. Pastore, Consumers' attitude and behavior towards online music piracy and subscriptionbased services, Journal of Consumer Marketing, vol. 31, no. 6/7, pp. 515-525, 2014.

[15] W. W. Chin, Modern Methods for Business Research, in The Partial Least Squares Approach for Structural Equation Modeling (G. A. Marcoulides, Ed.). Mahwah, NJ: Lawrence Erlbaum Associates, 1998, pp. 295-336.

[16] J.-S. Chiou, G.-y. Huang and H.-h. Lee, The antecedents of music piracy attitudes and intentions, Journal of Business Ethics, vol. 57, no. 2, pp. 161-174, 2005. 
[17] H. Cho, S. Chung and A. Filippova, Perceptions of social norms surrounding digital piracy: The effect of social projection and communication exposure on injunctive and descriptive social norms, Computers in Human Behavior, vol. 48, pp. 506-515, 2015.

[18] T. P. Cronan and S. Al-Rafee, Factors that influence the intention to pirate software and media, Journal of Business Ethics, vol. 78, no. 4, pp. 527-545, 2008.

[19] B. Culiberg, K. Koklic, I. Vida, and D. Bajde, Examining the effects of utilities and involvement on intentions to engage in digital piracy, Computers in Human Behavior, vol. 61, pp. 146-154, 2016.

[20] B. Culiberg, M. Kos Koklic, I. Vida, and D. Bajde, Examining the effects of utilities and involvement on intentions to engage in digital piracy, Computers in Human Behavior, vol. 61, pp. 146-154, 2016.

[21] B. M. Cunningham, P. J. Alexander and N. Adilov, Peer-to-peer file sharing communities, Information Economics and Policy, vol. 16, no. 2, p. 197, 2004.

[22] P. Ćwiakowski, M. Giergiczny and M. Krawczk, Pirates in the Lab: Using incentivized choice experiments to explore preference for (Un)authorized content, MIS Quarterly, vol. 40, no. 3, pp. 09-BBB707, 2016.

[23] A. d'Astous, F. Colbert and D. Montpetit, Music piracy on the web - How effective are anti-piracy arguments? Evidence from the theory of planned behavior, Journal of Consumer Policy, vol. 28, no. 3, pp. 289-310, 2005.

[24] F. D. Davis, Perceived usefulness, perceived ease of use, and user acceptance of information technology, MIS Quarterly, vol. 13, no. 3, pp. 319-340, 1989.

[25] C. De Corte and P. Van Kenhove, One sail fits all? A psychographic segmentation of digital pirates, Journal of Business Ethics, vol. 143, no. 3, pp. 441-465, 2017.

[26] R. Dias, D. Gonçalves and M. Fonseca, From manual to assisted playlist creation: A survey, Multimedia Tools \& Applications, vol. 76, no. 12, pp. 14375-14403, 2017

[27] C. M. Donner, C. D. Marcum, W. G. Jennings, G. E. Higgins, and J. Banfield, Low self-control and cybercrime: Exploring the utility of the general theory of crime beyond digital piracy, Computers in Human Behavior, vol. 34 , pp. 165-172, 2014.

[28] Edison_Research, Nielsen_Audio, and Triton_Digital, Popular online music brands among young people in the U.S. 2017, Transforming-radio.com, 2017.

[29] R. Faughnder. (2017, January) Home video sales shrank again in 2016 as Americans switched to streaming. Latimes. [Online]. Available: https://www.latimes.com/business/hollywood/la-fi-ct-home-video-decline-20170106 -story.html

[30] Fluent. (2017) Most popular music streaming services in the U.S. 2017. Fluentco.com. [Online]. Available: https://www.fluentco.com/resources/2017-facts-and-stats/

[31] J. P. Friedlander. (2018, May) News and notes on 2017 RIAA shipment and revenue statistics. RIAA. [Online]. Available: https://http://www.riaa.com/wp-content/uploads/2018/03/RIAA-Year-End-2017-News-andnotes.pdf\%3E

[32] T. Gallaway, J. H. Gallaway and D. Kinnear, The times they are a changin': Digital content supply decisions of students, Journal of Economics, vol. 32, no. 1, pp. 75-89, 20063.

[33] L. Gansky, The Mesh: Why the Future of Business is Sharing. New York: Portfolio. 2012.

[34] T. Geron, The share economy, Forbes, vol. 191, no. 2, pp. 58-58, 2013.

[35] F. F. Giancarlo, Digital piracy debunked: A short note on digital threats and intermediary liability, Internet Policy Review, vol. 5, no. 1, 2016.

[36] M. Glantz, Internet radio adopts a human touch: A study of 12 streaming music services, Journal of Radio \& Audio Media, vol. 23, no. 1, pp. 36-49, 2016.

[37] J. Greenberg. (2018, May) Apple doesn't need apple music to win, which is why it will. Wired. [Online]. Available: https://http://www.wired.com/2015/10/apple-doesnt-need-apple-music-to-win-which-is-why-it-will/\%3E

[38] J. F. Hair, W. C. Black, B. J. Babin, R. E. Anderson, and R. L. Tatham, Multivariate Data Analysis, 6th ed. New Jersey: Pearson-Prentice Hall, Upper Saddle River, 2006.

[39] W. Hampton-Sosa, An exploration of essential factors that influence music streaming adoption and the intention to engage in digital piracy, International Journal of Electronic Commerce Studies, vol. 8, no. 1, pp. 97-134, 2017.

[40] W. Hampton-Sosa, The impact of creativity and community facilitation on music streaming adoption and digital piracy, Computers in Human Behavior, vol. 69, pp. 444-453, 2017.

[41] H. v. d. Heijden, Factors influencing the usage of Websites: The case of a generic portal in The Netherlands, Information \& Management, vol. 40, no. 6, p. 541, 2003.

[42] H. v. d. Heijden, User acceptance of hedonic information systems, MIS Quarterly, vol. 28, no. 4, pp. 695-704, 2004.

[43] G. E. Higgins, Digital piracy: An examination of low self-control and motivation using short-term longitudinal data, CyberPsychology \& Behavior, vol. 10, no. 4, pp. 523-529, 2007

[44] G. E. Higgins, C. D. Marcum, T. L. Freiburger, and M. L. Ricketts, Examining the role of peer influence and selfcontrol on downloading behavior, Deviant Behavior, vol. 33, no. 5, pp. 412-423, 2012.

[45] G. E. Higgins, S. E. Wolfe and C. D. Marcum, Digital piracy: An examination of three measurements of selfcontrol, Deviant Behavior, vol. 29, no. 5, pp. 440-460, 2008.

[46] G. E. Higgins, S. E. Wolfe and M. L. Ricketts, Digital piracy: A latent class analysis, Social Science Computer Review, vol. 27, no. 1, pp. 24-40, 2009.

[47] M. Huhn, Liberate your Customers and Reap the Benefits, Marketing Review, 4:2 (2004), 225-246.

[48] IFPI. (2017) Global music report. IFPI. [Online]. Available: https://www.ifpi.org/downloads/GMR2017.pdf

[49] J. R. Ingram and S. Hinduja, Neutralizing music piracy: An empirical examination, Deviant Behavior, vol. 29 , no. 4, pp. 334-366, 2008. 
[50] Integr8_Research. (2017) Music platforms used by consumer in the U.S. 2017. integr8research.com. [Online]. Available: https://www.statista.com/statistics/253411/reasons-for-subscribing-to-streaming-music-services/

[51] Ipsos. (2017, September) Music consumer insight report. Ipsos. [Online]. Available: https://www.ifpi.org/ downloads/Music-Consumer-Insight-Report-2017.pdf

[52] Ipsos. (2016) Music consumer insight report. Ipsos. [Online]. Available: https://www.ifpi.org/downloads/MusicConsumer-Insight-Report-2016.pdf

[53] R. S. Jacobs, A. Heuvelman, M. Tan, and O. Peters, Digital movie piracy: A perspective on downloading behavior through social cognitive theory, Computers in Human Behavior, vol. 28 no. 3, pp. 958-967, 2012.

[54] J. Jarvis, What Would Google Do. New York: Harper Collins, 2009.

[55] I. Junglas, H. Koch, A. Sundararajan, and W. Ping, Editors' comments, MIS Quarterly Executive, vol. 16, no. 4, pp. iii-ix, 2017.

[56] E.-J. Ki, B.-H. Chang and H. Khang, Exploring influential factors on music piracy across countries, Journal of Communication, vol. 56, no. 2, pp. 406-426, 2006

[57] D. J. Kim, D. L. Ferrin and H. R. Rao, A trust-based consumer decision-making model in electronic commerce: The role of trust, perceived risk, and their antecedents, Decision Support Systems, vol. 44, no. 2, pp. 544-564, 2008.

[58] Y. Kjus, Musical exploration via streaming services: The Norwegian experience, Popular Communication, vol. 14, no. 3, pp. 127-136, 2016.

[59] M. K. Koklic, I. Vida, D. Bajde, and B. Culiberg, The study of perceived adverse effects of digital piracy and involvement: Insights from adult computer users, Behaviour \& Information Technology, vol. 33, no. 3, pp. 224235, 2014.

[60] M. Koufaris, Applying the technology acceptance model and flow theory to online consumer behavior, Information Systems Research, vol. 13, no. 2, pp. 205-223, 2002.

[61] M. Krawczyk, J. Tyrowicz, A. Kukla-Gryz, and W. Hardy, Piracy is not theft! Is it just students who think so?, Journal of Behavioral and Experimental Economics, vol. 54, pp. 32-39, 2015.

[62] G. Lalović, S. A. Reardon, I. Vida, and J. Reardon, Consumer decision model of intellectual property theft in emerging markets, Organizations \& Markets in Emerging Economies, vol. 3, no. 1, pp. 58-74, 2012.

[63] R. LaRose and J. Kim, Share, steal, or buy? A social cognitive perspective of music downloading, CyberPsychology \& Behavior, vol. 10, no. 2, pp. 267-277, 2007.

[64] M. Lee, H. Choi, D. Cho, and H. Lee, Cannibalizing or complementing? The impact of online streaming services on music record sales, Procedia Computer Science, vol. 91, pp. 662-671, 2016.

[65] Y. Lee, K. A. Kozar and K. R. T. Larsen, The technology acceptance model: Past, present, and future, Communications of the Association for Information Systems, vol. 12, pp. 752-780, 2003.

[66] A. M. Levin, M. C. Dato-on and C. Manolis, Deterring illegal downloading: The effects of threat appeals, past behavior, subjective norms, and attributions of harm, Journal of Consumer Behaviour, vol. 6, no. 2-3, pp. 111$122,2007$.

[67] T.-C. Lin, J. S.-C. Hsu and H.-C. Chen, Customer willingness to pay for online music: The role of free mentality, Journal of Electronic Commerce Research, vol. 14, no. 4, pp. 315-333, 2013.

[68] A. B. Lopes and D. F. Galletta, Consumer perceptions and willingness to pay for intrinsically motivated online content, Journal of Management Information Systems, vol. 23, no. 2, p. 203, 2006.

[69] P. B. Lowry, J. Zhang and T. Wu, Nature or nurture? A meta-analysis of the factors that maximize the prediction of digital piracy by using social cognitive theory as a framework, Computers in Human Behavior, vol. 68, pp. 104-120, 2017.

[70] S. Lysonski and S. Durvasula, Digital piracy of MP3s: consumer and ethical predispositions, The Journal of Consumer Marketing, vol. 25, no. 3, p. 167, 2008.

[71] J. Malin and B. J. Fowers, Adolescent self-control and music and movie piracy, Computers in Human Behavior, vol. 25, no. 3, pp. 718-722, 2009.

[72] N. Marangunic and A. Granic, Technology acceptance model: a literature review from 1986 to 2013, Universal Access in the Information Society, vol. 14, pp. 81-95, 2015.

[73] D. McCorkle, J. Reardon, D. Dalenberg, A. Pryor, and J. Wicks, Purchase or pirate: A model of consumer intellectual property theft, The Journal of Marketing Theory and Practice, vol. 20, no. 1, pp. 73-86, 2012.

[74] H. Mclntyre. (2017, August) These are the streaming music services the world has already lost. Forbes. [Online]. Available: http://www.forbes.com/sites/hughmcintyre/2017/08/15/these-are-the-streaming-music-services-theworld-has-already-lost/-d4b12f82cbba.

[75] J. McKenzie, Graduated response policies to digital piracy: Do they increase box office revenues of movies?, Information Economics and Policy, vol. 38, pp. 1-11, 2017

[76] A. Minniti and C. Vergari, Turning Piracy into Profits: a Theoretical Investigation, Information Economics \& Policy, vol. 22, no. 4, pp. 379-390, 2010.

[77] R. G. Morris and G. E. Higgins, Criminological theory in the digital age: The case of social learning theory and digital piracy, Journal of Criminal Justice, vol. 38, no. 4, pp. 470-480, 2010.

[78] J. H. Mortimer, C. Nosko and A. Sorensen, Supply responses to digital distribution: Recorded music and live performances, Information Economics \& Policy, vol. 24, no. 1, pp. 3-14, 2012.

[79] N. A. Morton and X. Koufteros, Intention to commit online music piracy and its antecedents: An empirical investigation, Structural Equation Modeling, vol. 15, no. 3, pp. 491-512, 2008.

[80] MusicWatch. (2016) Share of music buyers who pirate music in the U.S. 2015. Musicwatchinc.com. [Online]. Available: https://www.statista.com/statistics/216260/music-piracy-in-the-united-states/ 
[81] MUSO. (2016) Global piracy insights report. MUSO. [Online]. Available: https://www.muso.com/magazine/ musos-global-music-piracy-insight-report-2016-released/

[82] MUSO. (2018) Global piracy insights report. MUSO. [Online]. Available: https://www.muso.com/annual-piracyreports/

[83] MUSO. (2017) Global piracy insights report. MUSO. [Online]. Available: https://www.muso.com/magazine/ muso-releases-2017-global-film-tv-insight-report/

[84] A. Nandedkar and V. Midha, It won't happen to me: An assessment of optimism bias in music piracy, Computers in Human Behavior, vol.28, no.1, pp. 41-48, 2012

[85] K. Naveed, C. w. c. p. g. c. Watanabe and P. Neittaanmäki, Co-evolution between streaming and live music leads a way to the sustainable growth of music industry - Lessons from the US experiences, Technology in Society, vol. 50, pp. 1-19, 2017

[86] Netflix. (2018, May) Company profile. Netflix. [Online]. Available: https://ir.netflix.com/.

[87] NetNames, NetNames Piracy Analysis: Sizing the Piracy Universe. London, UK: NetNames, 2013.

[88] C. Nolter, Sense of the Markets: Tech Giants Wade Deeper into Streaming Music. The Deal Pipeline, 2014.

[89] F. Oberholzer-Gee and K. Strumpf, The effect of file sharing on record sales, revisited, Information Economics and Policy, vol. 37, pp. 61-66, 2016

[90] P. A. Pavlou and M. Fygenson, Understanding and predicting electronic commerce adoption: An extension of the theory of planned behavior, MIS Quarterly, vol. 30, no. 1, p. 115, 2016.

[91] P. A. Pavlou, L. Huigang, and X. Yajiong, Understanding and mitigating uncertainty in online exchange relationships: A principal-agent perspective, MIS Quarterly, vol. 31, no. 1, pp. 105-136, 2007.

[92] G. Peoples. (2016, April) What apple music and spotify's updated subscriber count really means, Billboard. [Online]. Available: http://www.billboard.com/articles/business/6836561/apple-music-spotify-subscriber-countanalysis\%3E.

[93] C. Peukert, J. Claussen and T. Kretschmer, Piracy and box office movie revenues: Evidence from megaupload, International Journal of Industrial Organization, vol. 52, pp. 188-215, 2017.

[94] I. Phau, A. Lim, J. Liang, and M. Lwin, Engaging in digital piracy of movies: a theory of planned behaviour approach, Internet Research, vol. 24, no. 2, pp. 246-266, 2014

[95] A. Piolatto and F. Schuett, Music piracy: A case of the rich get richer and the poor get poorer, Information Economics \& Policy, vol. 24, no. 1, pp. 30-39, 2012.

[96] P. M. Podsakoff and D. W. Organ, Self-reports in organizational research: Problems and prospects, Journal of Management, vol. 12, no. 4, pp. 531-544, 1986

[97] C. K. Prabalad and V. Ramaswamy, The Future of Competition: Co-creating Unique Value with Customers, Boston, MA: Harvard Business School Press, 2004.

[98] C. K. Prahalad and V. Ramaswamy, Co-creation experiences: The next practice in value creation, Journal of Interactive Marketing, vol. 18, no. 3 pp. 5-14, 2004.

[99] C. K. Prahalad and V. Ramaswamy, The new frontier of experience innovation, MIT Sloan Management Review, vol. 44, no. 4, pp. 12-18, 2003

[100] P. Resnikoff. (2016, April) There are nearly 90 million people paying for streaming music. Digital Music News. [Online]. Available: https://www.digitalmusicnews.com/2016/04/11/there-are-nearly-90-million-streaming-subscri bers-in-the-world/

[101] RIAA. (2017, June) News and notes on 2016 RIAA shipment and revenue statistics. RIAA. [Online]. Available: https://www.riaa.com/wp-content/uploads/2017/03/RIAA-2016-Year-End-News-Notes.pdf

[102] K. Robertson, L. McNeill, J. Green, and C. Roberts, Illegal downloading, ethical concern, and illegal behavior, Springer Science \& Business Media B.V., vol. 108, pp. 215-227, 2012.

[103]E. M. Rogers, Diffusion of Innovations, 5th ed. New York: Free Press, 2003.

[104]T. Schäfer, P. Sedlmeier, C. Städtler, and D. Huron, The psychological functions of music listening, Frontiers in Psychology, vol. 4, 2013.

[105]K. J. Shanahan and M. R. Hyman, Motivators and enablers of SCOURing: A study of online piracy in the US and UK, Journal of Business Research, vol. 63, no. 9/10, pp. 1095-1102, 2010.

[106]B. Sheehan, J. Tsao and J. Pokrywczynski, Stop the music!, Journal of Advertising Research, vol. 52, no. 3, pp. 309-321, 2012.

[107] B. Sheehan, J. Tsao and S. Yang, Motivations for gratifications of digital music piracy among college students, Atlantic Journal of Communication, vol. 18, no. 5, pp. 241-258, 2010.

[108] G. Sinclair and J. Tinson, Psychological ownership and music streaming consumption, Journal of Business Research, vol. 71, pp. 1-9, 2017.

[109] R. K. Sinha and N. Mandel, Preventing digital music piracy: The carrot or the stick?, Journal of Marketing, vol. 72, no. 1, p. 1, 2008.

[110]B. Sisario, Spotify Is Growing, But So Are Its Losses. New York: The New York Times, 2017.

[111]A. Smith, Shared, Collaborative and On Demand: The New Digital Economy, Internet and Technology. Washington, DC: Pew Research Center, 2016.

[112]A. R. Sorkin, A Big Reason Wall Street Is Flocking to Spotify: DealBook Briefing. New York: New York Times, 2018.

[113] Statista. (2017) Digital market outlook. Statista. [Online]. Available: https://www.statista.com/outlook/digitalmarkets

[114] A. Sundararajan, The Sharing Economy: The End of Employment and the Rise of Crowd-Based Capitalism. Cambridge: MIT Press, 2017. 
[115]A. Sundararajan, The Sharing Economy: The End of Employment and the Rise of Crowd-Based Capitalism. Cambridge: The MIT Press, 2016.

[116]M.-C. Tang and M.-Y. Yang, Evaluating music discovery tools on spotify: The role of user preference characteristics, Journal of Library and Information Studies, vol. 15, no. 1, pp. 1-16, 2017.

[117] S. A. Taylor, C. Ishida and D. W. Wallace, Intention to engage in digital piracy: A conceptual model and empirical test, Journal of Service Research, vol. 11. No. 3, pp. 246-262, 2009.

[118]S. Thomas. (2017) Independent music labels are creating their own streaming services to give artists a fair deal, The Conversation. [Online]: Available: https://theconversation.com/independent-music-labels-are-creating-theirown-streaming-services-to-give-artists-a-fair-deal-81578

[119] F. Tjiptono, D. Arli and D. Viviea, Gender and digital piracy: examining determinants of attitude toward digital piracy among youths in an emerging market, International Journal of Consumer Studies, vol. 40, no. 2, pp. 168178, 2016.

[120] G. Udo, K. Bagchi and M. Maity, Exploring factors affecting digital piracy using the norm activation and UTAUT models: The role of national culture, Journal of Business Ethics, vol. 135, no. 3, pp. 517-541, 2016.

[121]R. Uribe and C. Martínez, Factores que influencian la piratería de música digital desde internet en Chile, Estudios de Administración, vol. 16, no. 1, pp. 1-32, 2009.

[122] V. Venkatesh and F. D. Davis, A theoretical extension of the technology acceptance model: Four longitudinal field studies, Management Science, vol. 46, no. 2, p. 186, 2000.

[123] V. E. Vinzi, W. W. Chin, J. Henseler, and H. Wang, Handbook of Partial Least Squares: Concepts, Methods and Applications. New York: Springer Handbooks of Computational Statistics, 2010.

[124] C.-C. Wang, Factors that influence the piracy of DVD/VCD motion pictures, Journal of American Academy of Business, Cambridge, vol. 6, no. 1, p. 231, 2005.

[125] C.-c. Wang, C.-t. Chen, S.-c. Yang, and C.-k. Farn, Pirate or buy? The moderating effect of idolatry, Journal of Business Ethics, vol. 90, no. 1, pp. 81-93, 2009.

[126]X. Wang and S. R. McClung, The immorality of illegal downloading: The role of anticipated guilt and general emotions, Computers in Human Behavior, vol. 28, no. 1, p. 153, 2012.

[127]Y.-S. Wang, C.-H. Yeh and Y.-W. Liao, What drives purchase intention in the context of online content services? The moderating role of ethical self-efficacy for online piracy, International Journal of Information Management, vol. 33, no. 1, pp. 199-208, 2013.

[128] A. Washenko. (2018, March) RIAA 2017: Streaming leaps to 65\% share of U.S. music revenue, dominated by subscriptions. Rain News. [Online]. Available: https://rainnews.com/riaa-2017-streaming-leaps-to-65-share-ofu-s-music-revenue-dominated-by-subscriptions/

[129]B. Weijters and F. Goedertier, Understanding today's music acquisition mix: a latent class analysis of consumers' combined use of music platforms, Marketing Letters, vol. 27, no. 3, pp. 603-610, 2016.

[130]B. Weijters, F. Goedertier and S. Verstreken, Online music consumption in today's technological context: putting the influence of ethics in perspective, Journal of Business Ethics, vol. 124, no. 4, pp. 537-550, 2014.

[131]L. A. Wicht and J. Waldfogel. (2015) Streaming reaches flood stage: Does spotify stimulate or depress music sales?. European Commission, EU Science Hub. [Online]. Available: https://ec.europa.eu//irc/sites/ircsh/files/ JRC96951.pdf

[132] T. Wingrove, A. L. Korpas and V. Weisz, Why were millions of people not obeying the law? Motivational influences on non-compliance with the law in the case of music piracy, Psychology, Crime \& Law, vol. 17, no. 3, pp. 261-276, 2011.

[133] N. Wlömert and D. Papies, On-demand streaming services and music industry revenues-Insights from spotify's market entry, International Journal of Research in Marketing, vol. 33, no. 2, pp. 314-327, 2016.

[134]S. E. Wolfe, G. E. Higgins and C. D. Marcum, Deterrence and digital piracy: A preliminary examination of the role of viruses, Social Science Computer Review, vol. 26, no. 3, pp. 317-333, 2008.

[135]D. J. Woolley, The cynical pirate: How cynicism effects music piracy, Academy of Information \& Management Sciences Journal, vol. 13, no. 1, pp. 31-43, 2010.

[136]W.-P. Wu and H.-L. Yang, A comparative study of college students' ethical perception concerning internet piracy, Quality \& Quantity, vol. 47, no. 1, pp. 111-120, 2013.

[137]Z. Yang and J. Wang, Differential effects of social influence sources on self-reported music piracy, Decision Support Systems, vol. 69, pp. 70-81, 2015.

[138]N. Yaraghi and S. Ravi. (2017) The current and future state of the sharing economy. Brookings India, Chanakyapuri, New Delhi. [Online]. Available. https://www.brookings.edu/wp-content/uploads/2016/12/sharing economy 032017final.pdf

[139] C. Yoon, Digital piracy intention: a comparison of theoretical models, Behaviour \& Information Technology, vol. 31, no. 6, pp. 565-576, 2012.

[140]C. Yoon, Theory of planned behavior and ethics theory in digital piracy: An integrated model, Journal of Business Ethics, vol. 100, no. 3, pp. 405-417, 2011.

[141]L. Zhang, W. W. Smith and W. C. McDowell, Examining digital piracy: Self-control, punishment, and selfefficacy, Information Resources Management Journal, vol. 22, no. 1, pp. 24-44, 2009. 


\section{Appendix A: Measurement Instrument}

Respondents were asked to mark their answer to each of the questions using seven-level Likert scales. For all items, unless otherwise noted, $1=$ strongly disagree $-7=$ strongly agree.

\section{General Attitude Toward Unauthorized Downloading [39]}

- GATUD1. To me, unauthorized downloading of songs from P2P networks is:

$(1=$ very bad $-7=$ very good $)$

- $\quad$ GATUD2. To me, unauthorized downloading of songs from P2P networks is:

( $1=$ very unpleasant $-7=$ very pleasant $)$

- GATUD3. To me, unauthorized downloading of songs from P2P networks is: ( $1=$ very foolish $-7=$ very wise $)$

- GATUD4. To me, unauthorized downloading of songs from P2P networks is: $(1=$ very wrong $-7=$ very correct $)$

- GATUD5. To me, unauthorized downloading of songs from P2P networks is: ( $1=$ very unacceptable $-7=$ very acceptable)

\section{Likelihood of Setting up an Account}

- PI. After this study, how likely are you to set up a personal account at this website? $(1$ = very unlikely $-7=$ very likely $)$

\section{Unauthorized Downloading Intention [39]}

- UDI1. I may download unauthorized copies of songs from a P2P network in the future to avoid using this

- $\quad$ website for acquiring music. (Assume the song is available only from a P2P network or your assigned website.)

- UDI2. If I had the opportunity, I would download unauthorized songs from a P2P network to avoid using this website for acquiring music. (Assume the song is available only from a P2P network or your assigned website.)

- UDI3. I would never download unauthorized songs from a P2P network to avoid using this website for acquiring music. (Assume the song is available only from a P2P network or your assigned website.)

\section{Product Cost [39]}

- PC1. I feel that the price for music at this website is very inexpensive.

- $\quad$ PC2. In my opinion, music at this website is

$(1=$ very inexpensive -4 = just right -7 = very expensive $)$

- $\quad$ PC3. If I wanted to acquire music from this website today, it would cost me too much money.

\section{Perceived MSS Usefulness [39]}

- $\quad$ PMUA1. The website is useful.

- $\quad$ PMUA2. The website saves me time.

- $\quad$ PMUA3. The website helps me be productive.

- $\quad$ PMUA4. The website makes the task I want to accomplish easier to get done. 
- $\quad$ PMUA5. The website helps me be more effective.

- $\quad$ PMUA6. The website requires the fewest steps to accomplish what I want to do with it.

\section{Perceived MSS Enjoyment [39}

- $\quad$ PME1. To me, the website is enjoyable.

- $\quad$ PME2. To me, the website is exciting.

- $\quad$ PME3. To me, the website is unpleasant.

- $\quad$ PME4. To me, the website is boring.

- $\quad$ PME5. To me, the website is interesting.

- $\quad$ PME6. To me, the website is dull.

\section{Perceived MSS Ease of Use [39]}

- $\quad$ PMEOU1. The website is easy to use.

- $\quad$ PMEOU2. It is easy to become skillful at using the website.

- $\quad$ PMEOU3. Learning to operate the website is NOT easy.

- PMEOU4. The website is flexible to interact with.

- $\quad$ PMEOU5. My interaction with the website is clear and understandable.

\section{Perceived Product Format Usefulness [39]}

- $\quad$ PPFU1. The song format is useful.

- $\quad$ PPFU2. The song format improves my overall music consumption experience.

- $\quad$ PPFU3. The song format improves my overall music consumption performance.

- $\quad$ PPFU4. The song format does not enable me to consume music in the way I prefer.

- $\quad$ PPFU5. The song format enhances my overall effectiveness in consuming music.

- $\quad$ PPFU6. The song format makes it easier to consume music.

\section{Perceived Product Format Enjoyment [39]}

- $\quad$ PPFE1. To me, the song format from this website is enjoyable.

- $\quad$ PPFE2. To me, the song format from this website is exciting.

- $\quad$ PPFE3. To me the song format from this website is unpleasant.

- $\quad$ PPFE4. To me, the song format from this website is boring.

- $\quad$ PPFE5. To me, the song format from this website is interesting.

- $\quad$ PPFE6. To me, the song format from this website is dull. 


\section{Perceived Ease of Product Sharing (Adapted Scale) [39]}

- PEPS1. The songs from this website are easy to share with others.

- PEPS2. It is easy to choose with whom I can share songs from this website.

- PEPS3. Learning how to share songs from this website with others is NOT easy.

- PEPS4. The songs from this website are flexible regarding whether $\mathrm{I}$ can share them with others.

- PEPS5. How to share songs from this website with others is clear and understandable.

\section{Perceived Ease of Product Modification (Adapted Scale) [39]}

- PEPM1. The songs from this website are easy to modify for a variety of purposes.

- $\quad$ PEPM2. It is easy to become skillful at modifying songs from this website for different purposes.

- $\quad$ PEPM3. Learning to how to modify songs from this website for a variety of purposes is NOT easy.

- PEPM4. The songs from this website are flexible regarding the many ways they can be modified for different purposes.

- PEPM5. How to modify songs from this site for different purposes is clear and understandable.

Perceived Ease of Product Trial (Adapted Scale) [39]

- PEPT1. The songs from this website are easy to try out before making a commitment to acquire them.

- PEPT2. It is NOT easy to sample songs from this website before making a commitment to acquire them.

- PEPT3. Learning how to sample songs from this website before making a commitment to acquire them is easy.

- PEPT4. The songs from this website are flexible regarding whether I can try them out before making a commitment to acquire them.

- PEPT5. How to sample songs from this website before making a commitment to acquire them is clear and understandable.

\section{Perceived Product Format Usefulness [39]}

- PPFU1. The song format is useful.

- PPFU2. The song format improves my overall music consumption experience.

- PPFU3. The song format improves my overall music consumption performance.

- PPFU4. The song format does not enable me to consume music in the way I prefer.

- PPFU5. The song format enhances my overall effectiveness in consuming music.

- PPFU6. The song format makes it easier to consume music.

\section{Perceived Product Format Enjoyment [39]}

- PPFE1. To me, the song format from this website is enjoyable. 
- $\quad$ PPFE2. To me, the song format from this website is exciting.

- $\quad$ PPFE3. To me the song format from this website is unpleasant.

- $\quad$ PPFE4. To me, the song format from this website is boring.

- $\quad$ PPFE5. To me, the song format from this website is interesting.

- $\quad$ PPFE6. To me, the song format from this website is dull. 